\title{
SOBRE LA NOCIÓN DE "THES PERI PHYSEOS EPISTEMES"
}

Eloy RADA

UNED, Dpto. De Lógica y Filosofia de la Ciencia

Tentativamente me propongo sugerir en este ensayo i) que la noción inicial y primitiva de episteme fisica utilizada por Aristóteles no se corresponde con la noción de "ciencia" demostrativamente articulada, que se le atribuye; ii) que inicialmente era una noción perteneciente a su idea más general de "dialéctica"; iii) que los recursos al análisis de términos y a la silogistica eran herramientas epistémicas inicialmente integradas en su noción de "dialéctica"; iv) que este arsenal dialéctico-epistémico, articulado por Aristóteles, muy probablemente centró su primer objetivo en el discurso argumentado de Zenón y Meliso, discurso que "demostraria" las tesis inmovilistas de los eléatas; v) que la "interpretación", ayudada de la historia real posterior, reorientó el discurso aristotélico sobre la episteme física hacia una concepción más cercana a la moderna y actual.

\section{Una definición inicial.}

La ciencia, o "conocimiento y sistematización del mismo"1 en opinión de Aristóteles, debe a éste algunos de sus logros históricos $y$, tal vez, no menos problemas y bloqueos. Suele atribuirsele la primera conceptualización precisa de la idea de "ciencia", noción heredada de él, según se dice, e ininterrumpidamente mantenida

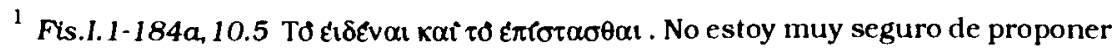

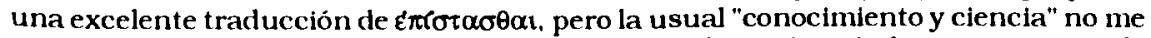
parece suficiente, porque ¿qué puede querer decir Aristóteles con esto de (literalmente) "ser epistemizado"?; émıothuaı , a la postre. tiene que ver con la idea

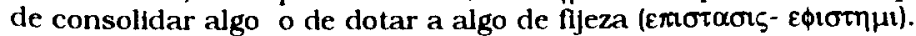

Endaxa: Series Filosóficas n 1, 1993, UNED, Madrid: Eloy RADA, Sobre la noción de "thes peri physeos epistemes. pp. $71 \cdot 108$ 
hasta nuestros dias. No resulta, sin embargo, evidente que la idea actual- digamos contemporánea, para no referirnos a una definición estricta y concreta- de "conocimiento y sistematización del mismo". cuando de conocimiento científico se trata, se corresponda enteramente con lo que Aristóteles trató de elucidar como episteme en alguno de los textos que suelen dar apoyo a la teoria, llamémosla, fundacionalista.

Precisamente en el inicio mismo de ese gran texto ${ }^{2}$ aristotélico que es la Fisica aparecen, vinculados a la noción de episteme, tres términos, en gran medida acuñados por él, cuya elucidación ocupó a Aristóteles muchas páginas, quizá más de la cuenta, y cuya presencia en la filosofia primero, y en la ciencia inicial después, significó estímulos y rémoras casi por igual. Si tomásemos a la historia por testigo, nos resultaria harto dificil justificar la atribución a estos textos aristotélicos del carácter fundacional de la idea de "ciencia" de la que ahora participamos. Y, aunque sean muchas las deudas contraidas con ellos, y con otros paralelos de la Metafísica, etc.. resulta más que problemático atribuirles una eficacia fundacional que, a nuestro entender, es debida más a la interpretación a que se han visto sometidos, históricamente corregida por los resultados de los saberes parciales e incipientes, que a su propio e inicial sentido. Trataré de acercarme a algunos de los perfiles que, al menos en parte, habrian delimitado este sentido inicial para que asi, como de paso y en escorzo, resulte insinuada la distancia recorrida por el concepto de "ciencia" desde la Fisica aristotélica hasta nuestros días.

El Lb.I de la Física se abre con un planteamiento en el que se ha querido ver tanto una expresión básica de la noción aristotélica de episteme, como una formulación canónica de la idea heredada de scientia.

\footnotetext{
${ }^{2}$ Las consideraciones que siguen obedecen básicamente a una relectura de los Lbs. I y II de la Fisica, en la hipótesis harto probable de que fuesen escritos muy al principio de sus trabajos filosóficos y más relacionados con otros escritos contemporáneos que con los restantes a los que se agregaron en la ediclón de Andrónico. Por otra parte, parece ser que hay argumentos para creer que el orden posible en la escritura de estos textos pudo ser $: 1^{\circ}$ Fisica VII- Lambda. Fisica I y II. Organon (parcialmente), $2^{\circ}$ Fisica III -VI. De Generatione et C.. De Caelo I-II. $3^{\prime}$ Física VIII, etc.
} 
Dice Aristóteles:

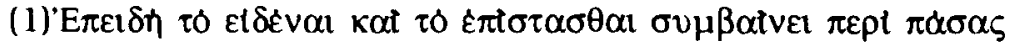

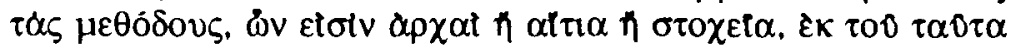

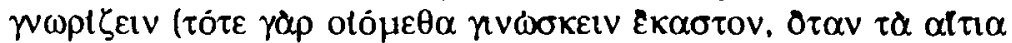

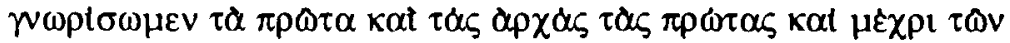

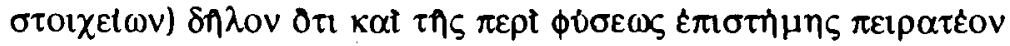

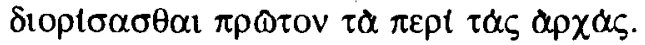

En la traducción de Guillermo de Moerbecke- a cuyo texto se atiene el comentario de $\mathrm{T}$. de Aquino- es trasladado como sigue:

(1a)Quoniam quidem intelligere et scire contingit circa omnes scientias, quarum sunt principia aut causae aut elementa, ex horum cognitione (tunc enim cognoscere arbitramur unumquodque, cum causas primas et prima principia cognoscimus, et usque ad elementa) manifestum quidem quod quae sunt circa principia scientiae quae de natura est, prius determinare tentandum.

En la versión utilizada por los conimbricenses como base de su comentario se dice:

(1b)Cum in omnibus doctrinis, quarum sunt principia, aut caussae, aut elementa, cognitio et scientia ex horum cognitione oriatur, (si quidem unumquodque tum nosse arbitramur, cum caussas primas noverimus, et principia prima, et usque ad elementa) patet Naturalis quoque scientiae ea primum definire enitendum esse, quae ad principia attinent.

Ciertamente se observan, a primera vista, algunas distancias de interpretación, p.e. methodos es "scientia" en (a) y "doctrina" en (b); mientras que en ambos gnorizein aparece como "cognoscere" o diorisaszai es "determinare" en (a) y "definire" en (b). Aparentemente estos desacuerdos no representan entre ellos más que matices, mientras que son algo más que matices lo que representan respecto al original. Los "comentarios", sin embargo, representan entre sí distancias más notables, aunque permaneciendo fieles a la misma tradición de fondo. En todo caso, fuera lo que fuese lo que en (1) Aristóteles quiso decir, (a) y (b) representan lo que se le ha hecho decir o lo que la interpretación ha estado interesada en que dijera. 


\section{Los principios y la "ciencia común a todas": El contexto de su investigación.}

Aristóteles acuñó una expresión conjunta, "principios, causas y elementos"3, para explicar la forma en que se debería producir el conocimiento, y la sistematización que de él se hiciese, forma que, por otra parte, nada tiene de espontánea o natural ${ }^{4}$. $Y$ añade que, en el saber sobre la Physis, es evidente que hay que empezar por alcanzar la elucidación- definición ${ }^{5}$ de los principios, tás óp $\chi \alpha \zeta$. Toda la argumentación inicial (hasta el cap. 5\%) del Lib I parece destinada a eliminar, por incongruentes o falaces, las propuestas de los "antiguos" incompletas o incompatibles con su primera tesis explícita del cap. $6^{6}$ : que los elementos (aqui claramente en intercambio constante con principios del movimiento) son tres y solo tres.

${ }^{3}$ Hay que notar que Aristóteles en este lugar utiliza además tres verbos que gradúan la forma del conocimiento mentado por estos términos.Son: દ́ı́́vat, $\varepsilon \pi\lceil\sigma \tau \alpha \sigma \theta \alpha 1, \gamma \omega p\ulcorner\zeta \varepsilon i v$. Este último parece en todo caso el más indefinible de los tres y la "penetración" o "intuición" (acquitance?) que menciogna no resulta directamente "epistemizable". Los Conimbricenses entienden que aqui se habla de dos formas de conocimiento: "alia definitiva est. alia demonstrativa". Parece que no perciben que Aristóteles usa tres verbos, quizá porque en la traducción latina el primero y el tercero se identifican como "cognoscere". Confer. Commentarii Conimbricenses in octo Libros Physicorum Aristotelis. L.l.Cap. I. Q.1.

${ }^{4}$ Recuérdese la frase. casi inicial. "No es lo mismo lo más cognoscible para nosotros que lo más cognoscible absolutamente". De hecho los principios. las causas y los elementos acaban por ser identificados, conocidos y sistematizados tras un proceso de análisis, similar al que ocurre en las definiciones. vide Física, 1, 184a 16$184 \mathrm{~b} 14$.

${ }^{5}$ Aristóteles utiliza el verbo

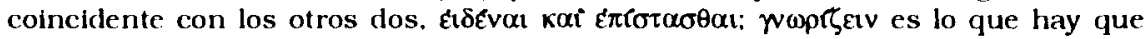
hacer con los principios. y una vez hecho eso con los principios causas y elementos.

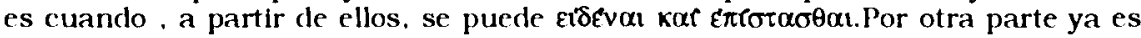
conocida su tesis de que los principios no son objeto de demostración. De igual manera vuelve a utilizar este verbo en el párrafo siguiente (184a. 16-26) al discutir el proceso "más adecuado" en la investigación y arguye "de lo más intuible o

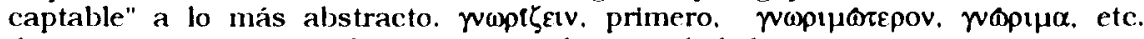
después, no parecen referirse tanto a la actividad de construir u organizar un conocimiento como a la adquisición de una situación desde la que esto sea posible. De hecho en (la) para este segundo párrafo se propone "notus et certius" y en (lb) "notus et manifestus", lejos del "cognoscere" inmediatamente anterior.

${ }^{6}$ Confer. 189a. 11 y stss. 


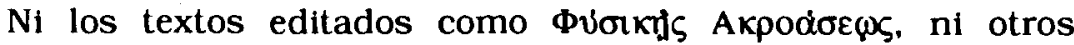
asimilables a estos, permiten suponer que Aristóteles estableciera distinciones precisas entre estos tres têrminos, aunque parece claro que atribuyó a la suma o convergencia de sus significados un alcance según el cual tanto podrian dar cuenta del movimiento de la naturaleza misma, la Physis, como del conocimiento y sistematización del mismo que generan ( o contribuyen a generar), -la $\pi \varepsilon \rho i$

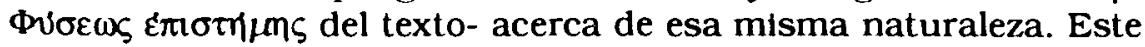
complejo conceptual ha admitido múltiples interpretaciones, y la critica moderna, ayudada del uso escolar heredado ${ }^{7}$, ha establecido

7 T. de Aquino hace el siguiente análisis de estos tres térninos: "Per hoc autem quod dicit principia aut causas aut elementa. non intendit idem significare. Nam causa est in plus quam elementum; elementum enim est ex quo componitur res primo et est in eo, ut dicitur in V Mctaphys. sicut litterae sunt elementa locutionis, non syllabae: causae autem dicuntur ex quibus aliqua dependent secundum suum esse aut fieri: unde etiam quae sunt extra rem. vel quae sunt in re ex quibus non componitur res primo, possunt dici causae, non tamen elementa. Principium vero importat quendam ordinem alicuius procesus; unde aliquid potest esse principium. quod non est causa: sicut id unde incipit motus est principium motus, non tamen causa.

Sic igitur per principia videtur intelligere causas moventes et agentes, in quibus maxime attenditur orlo processus cuiusdam: per causas autem videtur intelligere causas formales et finales, a quilus maxime dependent res secundum suum esse et fieri; per elementa vero proprie primas causas materiales.

Utitur autem istis nominibus disiunctim et non copulatim ad designandum quod non omnis seientia per omnes causas demonstrat. Nam mathematica non demostrat nisi per causam formalem : metaphysica demonstrat per causam formalem et finalem precipue, et etiam agentem; naturalis autem per omnes causas". Confer. In octo Lib. physicorum Aristotelis Expositio. L.1.1 - 1.5. Mucho más elaborado se halla el asunto cuando llega a manos de los Conimbricenses. quienes dedican a los términos "principia, aut caussa" la siguiente aclaración: "Est hoc loco non parva inter latinos. Graecos. Arabesque dissentio quid sibi velint, quove dissideant tria illa, principium. caussa, et elementum. Alexander Eudemum secutus, et $D$. Thomas, per principium, caussam agentem significari putant: per caussam. formam et finem. per elementa. materiam. Averroes et Albertus per principia. caussam efficientem: per caussas, finem: per elementa. formam et materiam intelligunt. Alii tria haec inter se rationem habere. ut primum latius pateat secundo. secundum tertio. In quo sensu interdum sumi apud Aristotelem patet ex capite primo. secundo et 3 libro quinto Metaphisicac. Sub hac ve ro notione accept um principium definitur tum aliter in libro Poëticae cap.7. et libro quinto de generatione animalium, capite septimo: tum hoc modo . libr. 5. Metaphy. cap.1. Principium est id, unde aliquid est, fit, aut cognoseitur; sieque non modo omnes caussae, sed alia etiam multa, quae caussae non sunt, principia nuncupantur: veluti teminus. a quo generatio progreditur. qui principium est generationis. non caussa: item principium viae. aliaque id genus complura. Caussa vero est, quae confert esse rei. vel fovendo, et suscipiendo, ut materia: vel informando. atque actuando, ut forma: vel efficiendo, ut agens: vel 
valores preferentes para cada uno de esos términos, tanto en los contextos de la filosofia aristotélica como de la ciencia clásica o de la Filosofia actual. Pero a todas luces no seria necesariamente asi en el momento en que Aristóteles los proponia para introducir los fundamentos de su investigación sobre la Physis. Y, como confirmación, resultan demasiado numerosas las veces en que Aristóteles utiliza $\alpha \rho \chi \alpha i$, $\alpha$ țı $\alpha$, $\sigma \tau o \imath \chi \varepsilon i \alpha$, con un valor casi idéntico. Una pequeña diferencia, no obstante. pudiera hallarse en la preferencia

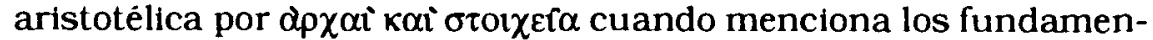
tos o lo "primordial" que buscaba la ciencia de los antiguos ${ }^{8}$, con

finalizando (liceat enim ita loqui) ut finis. Elementum autem est ipsa materia."

Y tras esta recopilación exacta y escueta. el comentarista añade algo importante que esconde en un cierto anonimato colectivo: "Denique recentium interpretum nonnulli asserunt. etsi horum vocabulorum unum ad unum genus caussae, aliud ad aliud interdum acommodetur; hoc tamen loco minime id fieri, neque ut flat, ullam esse rationem. Itaque idem singula, et universa significare, nec nisi ornatus, vel maioris explicationis gratia, tria pariter adhibita fuisse: ac si diceret Aristoteles, quomodocumque caussae nominentur. seu caussae. seu principia. seu elementa: ab ipsarum cognitione reliquorum intelligentiam pendere. Nam....<locet Arist.> universim in qualibet scientia contemplatrice <subr. nuest.> principia esse, caussas et elementa. id est. initia quaedam doctrinae: qualia sunt prima. et notissima effata. quae dignitates appellantur. quibus caetera tanquam fundamentis inituntur." O.c. pgs.46-47. Evidentemente aquí la Fisica. además de ser Fislologia (más acorde con Aristóteles) no es vista como ciencia empirica (pues la considera "contemplatrice") y los principios de que se siguiera no pertenecerian, ni por asomo,más que al campo de estudio de lo que la propia tradición convirtió en Metafisica ( en "ciencia contemplativa"). Que no le faltaban razones para ello parece evidente ( aunque fueran razones acompañadas de imposibilidad de critica textual) pero, por otra parte. no se puede ocultar al lector de nuestros dias que esas razones forzosas hacen violencia a un texto que trata de hacer inteligible y no contradictorio el concepto de generación. de cambio. crecimiento y desaparición de escena, experiencias inmediatas y que no necesitan pruebas de su existencia.

${ }^{8}$ Así,p.e. en Metph A3,983,b3; o en Fis.1-184b.25; 191a, 23. (" solo así se resuelven las dificultacles de los antiguos"). Sobre este extremo es digno de tenerse en cuenta el hecho de que arjai es un térnino puramente aristotélico bajo el que trata de sistematizar las cuestiones naturales de los antiguos, como dice J.Bumet: "La palabra arje, mediante la que los primeros cosmólogos, suelen ser caracterizados de haber designado el objeto de su investigación. es. en este sentido. puramente aristotélica.... No se halla más que en los manuales estoicos y peripatéticos de los que se derivan la mayor parte de nuestros conocimientos, y estos manuales simplemente repiten a Aristöteles. Zeller ha señalado.. que seria un anacronismo asignar a los comienzos de la especulación el uso sutil que Aristóteles hace de este término." (trad. nuestra) Confr. J.Burnet. 1970. pgs.13-14. Lo mismo mantiene G.E.R. Lloyd en su 1987 (1966), pg. 218 y nt.37. Ambos se hacen eco de la polémlca suscitada por la interpretación de un texto de Theofrasto sobre Anaximandro, y 
lo cual tenemos cierta sospecha de que la investigación de Aristóteles vuelve (siquiera por aquello de que era un gran lector) sobre algunos temas y sobre algunos argumentos ( como es el caso de los contrarios o de lo uno y lo múltiple) de modo casi literal ${ }^{9}$

Sin embargo, y aunque se tenga siempre presente, no seria prudente abusar de esta sospecha porque son muchos los pasajes en que Aristóteles utiliza la mencionada expresión, completa o parcial, con autonomia, con valores nuevos tan evidentes que impiden una interpretación arcaizante (como en el caso de su introducción de nuevo significado para arjai) de esos términos. Más bien hay que pensar que Aristóteles amplia el alcance, inicialmente no filosófico, de los mismos hasta hacerlos útiles ${ }^{10}$ dentro de su propia concepción: Ya aparece este deslizamiento en el Lib.l de la Fisica:

(2)

"Indagan lo mismo" < los que investigan cuántos son los principios, $\alpha p \chi \alpha,>$ " que los que investigan cuántos son los entes. Pues ya que de ellos < ¿de los entes?> están hechas las cosas que existen, primero investigan si son más bien uno que muchos y, si son muchos, si en número limitado o ilimitado.al modo como también quienes investigan el

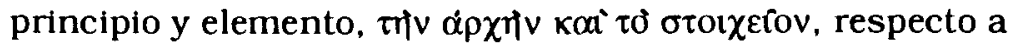
si es uno o múltiple"1!.

coinciden en que es un todo de hablar de Theofrasto, algo parecido al histortador que denominase "artilleria" a las catapultas de las legiones romanas.

${ }^{9}$ Algo digno de notarse es que Aristóteles en estos dos Libros parece centrarse en mostrar las condiciones en la cuales es posible formular el concepto de generación como paradigma de movimiento. Incluso parece que se esfuerza en hacer ver que su propuesta es nueva. original y distinta de las que sobre esta cuestión tradicional ha leido o ha escuchado en la Academia. Asi en los Caps. 8-9 del Lb.I habla con énfasis en primera persona al proponer "nuestra" opinión. Por otra parte. podriamos añadir que, aunque dificil de determinar, no solo hay algo nuevo y original en lo que él mismo dice. sino también en lo que hace decir a "los antiguos", de tal modo que parte de la doxografia presocrática es aristotélica y por lo mismo los antiguos se nos han trasmitido, en parte, "aristotelizados". El peso de las "Interpretaciones" resulta asi mucho mayor en la configuración histórica del pensamiento y este mucho más "diałógico" en su naturaleza y en su constitución. Confr. Chemiss. 1935.

${ }^{10}$ Como ejemplo arje que solo significaba anterior o principal. Confr. G.E.R. Lloyd. 1987. (1966). pg 218.

${ }^{11}$ Fis. $1-184 b, 22-25$. 
Además de omitir "las causas", ( término que ya Platón habia ligado con el hacer demiúrgico o divino), esta afirmación aristotélica encierra alguna perplejidad. Investigar el ente, cosa que hizo Parménides y también Platón $\mathbf{y}$, por supuesto, está también dispuesto a hacer él mismo, es hacer lo mismo que hicieron los antiguos cuando investigaban los principios y los elementos (nombres puestos por Aristóteles al "objeto" de la investigación de los "antiguos"). Esto equivale a: lo que hacen Parménides, Zenón y Meliso es lo mismo que lo que hacieron los fisikoi jonios antiguos. Parece que hay que suponer que Aristóteles también presupone alguna diferencia entre ambas investigaciones, toda vez que, a renglón seguido, afirma que investigar si el ente es uno e inmóvil ${ }^{12}$ no es una investigación que pertenezca a la Fisica:

(3)

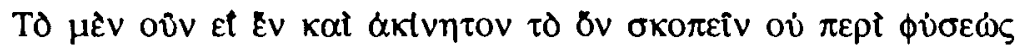

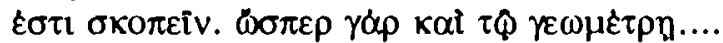

Pero. ¿cómo y por qué, en cambio, sí pertenecería a la Fisica la

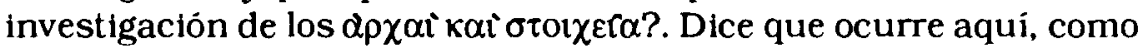
le ocurre al geómetra que no tiene argumentos contra quien le niegue los $\alpha \rho \chi \alpha i$ de su ciencia, necesitando entonces de otra ciencia (o de una común a todas), exactamente lo que ocurre al "fisico" que

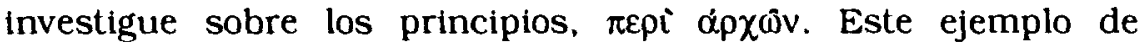
Aristóteles quizá pueda servir para ilustrar su propia posición respecto a la distancia que trata de establecer con sus predecesores (aqui representados por los geómetras carentes de "principios"), distancia que obliga a instalarse en la perspectiva de una ciencia nueva (de la cual no tuvieron idea ni los predecesor que trataron de investigar en Fisica sin "principios", ni los geómetras del ejemplo). No estoy convencido de que esta ciencia común a todas fuese, en la mente del Aristóteles que escribia este texto, la llamada Filosofia Primera, o la Metafisica de la recepción de Andrónico, o cualquier otra combinación de textos del Corpus. Tampoco me parece, en cambio, que partes enteras de esos textos, lógicos, físicos o

12 Aqui hay que destacar que los principales argumentos en pro de la unidad $e$ inmovilidad del ente son los propuestos por Zenon y Meliso. Los elementos de Empédocles. junto con el apeiron de Anaximand ro no permiten a Aristóteles articular un argumento definitivo ni siquiera con la incorporación de la idea de mediación, la metaxu. 
metafisicos, puedan desconectarse de la idea aristotélica de ciencia común a todas, idea que me parece muy temprana en el pensamiento de Aristóteles y bastante determinada por los análisis dialécticos propios de su época de la Academia. En todo caso hay que subrayar que "común a todas" no equivale a "primera". Pero el núcleo de esa ciencia, que seria capaz de dar cuenta de todas las demás en razón de poder darla de los principios, causas y elementos, dudo que llegase a ser sistematizado en un escrito concreto por Aristóteles, aunque se pueda aventurar que algunos capitulos prologales, o incluso centrales para su inicial proyecto, quedasen muy avanzados (como seria el caso de parte del Organon ${ }^{13}$ ).

\section{Interpretaciones "interesadas".}

Resulta al menos curioso, por no decir desconcertante, que, bien por la organización dada a los escritos aristotélicos en la edición de Andrónico, bien por otras causas, viniese a ser la Metafísica ${ }^{14}$, un

\footnotetext{
${ }^{13}$ Algunos pasajes de Tópicos y de Refutaciones Sofisticas me hacen sospechar que i)Aristóteles escribió estos tratados directamente contra los sofistas, representados en el momento por la escuela de Isócrates (quizá tamblén como "su" homenaje a Sócrates) y. supuesto el enorme prestigio de la sofistica entre los atenienses, para recuperar para la filosofia el campo de influencia que estos conocimientos o "artes" tenian en aquella sociedad. El texto que me permite abrigar esta sospecha ( aunque hubiese sido añadido en una revisión posterior a la redacción inicial) es la Conclusión de Refutaciones Sofisticas $(34,183 a .24$ y stts hasta el final del libro).ii) Que la dialéctica, suponiendo que Tópicos y Refutaciones Sofisticas obedezcan a este plan, junto con Categorias, (que parece insinuado en el texto mencionado en 183a 38-41). como se presenta en Tópicos 1,10, desde 104a en adelante hasta el final de la obra junto con Refutaciones es el centro del programa de recuperación de la propia dialéctica del bastardeo (parentesco.según la prudente denominación aristotélica) sofistico.Debo aclarar, antes de seguir adelante, que la lectura de las tres obras que aqui menciono determinan básicamente la lectura que propongo de los textos más primitivos de la Fisica.

14 En este punto mil mejor fuente de información ha sido el estudio de I.Düring (Düring 1966) de cuya "organización secuencial"de los escritos del Corpus no resulta discrepante la interpretación que aqui hago. Por lo demás, Düring separa los dos primems libros de la Física como unidad cercana al libro "lambda" de la Metafisica y no distante de partes muy notables del "Organon". Me atengo a esta idea como marco de estas consideraciones. Por otra parte suele aducirse como prueba de la unidad de estos escritos sobre Física, el hecho de que aparezcan mencionados de manera aparentemente unitaria en las dos primeras lineas de los Meteoros. Dice: "Ya hemos tratado de las primeras causas de la naturaleza y de todo movimiento natural. así como de los regulares desplazamientos de los astros de arriba y de cuántos, y
} 
anárquico conglomerado de escritos inconclusos a veces o de resúmenes de cursos y esquemas de clases $^{15}$ sin desarrollar, el sucedáneo de esa ciencia común. Me parece que semejante suplan-

cuáles son los elementos de los cuerpos, y de los cambios entre ellos, y de la generación y la corrupción en general". Meteoros. I,338a,20-24. Suponiendo que estas lineas sean originales ( y no un engarce "editorial" añadido como transictón entre los textos editados) hay que subrayar que resultan mencionados independientemente, primero el estudio de las causas de la naturaleza ( se referiria a los Lbs. 1 y 2 de la Fisica, principalmentel y despues el estudio del cambio y movimiento (Lbs. 3-6), después el estudio del Clelo, etc. Si esta mención de sus estudios se lee como una mención individualizada de cada uno de ellos ( y por tanto suponiendo una graduación de más lejano a más cercano) resulta patente la independencia atribuida a los dos primeros Libros. o al menos. su autonomia.

15 La tradición ha visto estos escritos de Aristóteles como fruto de su labor más seria o profesional y haciéndose eco del titulo (akroasis) de esta obra estableció niveles de exposición y de investigación en la labor de Aristóteles. Los Conumbricenses lo resumen (para el caso de los 8 libros de la Fisica) como sigue: "(observatum est).. Aristotelem duo edidisse librorum genera (quam etiam scribendi rationem secutum fuisse Theophrastum refert Cicero loco proxime citato, et Galenus

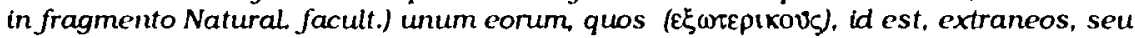
populares nuncupavit, quorum ipse mentionem facit 1. de moribus ad Eudemum cap.5.

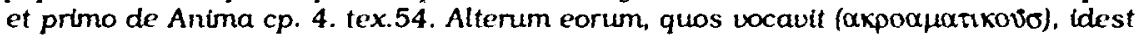
Auscultatorios, quorum item meminit in epistola ad Alexandrum, quam refert Gellius 1i.20. c.4. addens more fuisse Aristotelh Acroamaticae disciplinae exercendae matutinum tempus in lyceo dare; Exotericae autem vespertinum Et vero priores libri faciliorem, ac minus elaboratam rationem scribendi rationem continent, quales sunt ii, in quibus Poëseos, et Rhetoricae praecepta, aut animalium historia traditur. Ideoque Exoterich, seu extranel nuncupantur, quod ad vulgi sensum, captumque acommodati sint, et interpretis vacem minus requirant. Posteriorts autem subtlioris Philosophiae doctinam a vulgar genere philosophandi, et popularibus sententiis abhorrentem complectuntur: atque it a Auscultatoril vacantur, propterea quod et a discipulis maiort studio, attentioneque audiendi, et a magistris accuratius enarrandi sint.... Cur autem hi (sc. Physici) potissimum inter cacteros Acroamaticos, hoc titulo praenotentur. caussa esse videtur, quod ad totam physicam introducant, eiusque prima fundamenta et multas, ac difficiles quaestiones in se contineant, proindeque, ut hoc loco advertit Psellus, peculiariter de magistro audiendi sint". Cfr. Comentarrii Conimbricenses in octo Libros Physicorum Aristotelis . Prooem. Q. V. Art. 4. Lugduni. Sumptibus Joannes Babtistae Buysson. 1594. pg.43. La critica moderna ha establecido, en cambio, que partes importantes de estos escritos no fueron lecciones matutinas y acroásticas del Lycco. sino escritos muy anteriores realizados en un contexto muy diferente: el de la Academia. Pero la tradición - incluso la griega-consideró a la Fisica como una obra unitaria y redactada para la publicación. También de ello se hacen eco los Conimbricenses: "Putat autem Simplicius hos esse libros <sc. Phystcos> de quorum editione Alexander Macedo cum Arist. per literas expostulavit, cum non imperio tantum, et rei bellicae gloria, sed scientia quoque cacteris mortalibus anteire cuperet, quam laudem ademptam sibi existimabat evulgata abditissimarum rerum, quae in hoc opere continentur, explicatione. Plutarchus tamen in vita Alexandri non de his, sed de Mataphysicis, Regis quacrimoniam interpretatur."Ibd. 
tación (no es un consuelo constatar que ni Alejandro de Afrodisia ni los demás comentaristas griegos o latinos resulten ser siempre los iniciadores del "aristotelismo" de la tradición) fabricada por la interpretación posterior es uno de los más graves inconvenientes que el aristotelismo heredado "añadió" por su cuenta a nuestra comprensión de la idea de episteme que Aristóteles pretendia establecer desde o mediante esa "ciencia común a todas". De no haber ocurrido esto, sospecho, la noción aristotélica de episteme habria cedido paso a otras ideas menos cargadas de "filosofia primera", como, quizá, la de los atomistas.

$Y$, aunque sea por via de mera sugerencia o, si se quiere, de caritativo consuelo historicista, podemos aventurar que la recepción escolástica se encontró, por causa, entre otras cosas, de esa edición de Andrónico con una limitación textual insuperable para ir en busca de esa ciencia común ${ }^{16}$. limitación agravada hasta limites dramáticos debido a la intromisión de la teologia judeo-platónica entre las "ciencias" que necesitan encontrar, a la vez que dar ${ }^{17}$.

16 Que la tradición solo halló uniclad y coherencia en los escritos de Aristótelesaún en los que solo gozaban de unidad de encuademación- viene ya determinado por los comentaristas primeros. Los Conimbricenses - en el breve Proemium al lb.I de la Fisica - se hacen lenguas de la coherencia < ordo et dispositio> interna de la obra entera y en concreto de la Fisica "Hinc illa Aristotelis Physiologia continuata series, atque omnium partium sese mutuo. et decenter excipientium. quasi in unius corporis structuram, conspiratio. Quo certe Philosophus, alioqui, in Acroamaticis praesertim libris minime perspicuitatis affectator, illud est assecutus, ut rerum difficultatem artificiosa tractandi commoditate mirifice condierit, et quasi affuso lumine collustrarit. Hane igitur doctrinae suae methodum. et seriem proponit Aristoteles in prima huius libri parte <sc. lib. I Physicorum>; quae praefationem continet, et uno capite absolvitur. Secundum vero, quae reliquis octo capitibus comprehenditur, totam de rerum Physicarum principia investiganda confert.... Porro Alexander Aphrodisiensis. initio libri secundi Metaphysicorum, opinatus est eum librum esse toti comtemplatrici Philosophiae commune proemium: atque adeo ad hunc locum attinere. Nobis tamen contraria sententia, quam omnes Graeci. latínique interpretes amplexi sunt. omnino probatur; maxime cum ea. de quibus Aristoteles eo libro disserit, non ad Physicam, sed ad primam Philosophiam spectent. ut erit legenti perspicuum". Cnfer. Conimbricenses. O.c. pg. 45.

17 La noción de "verdad revelada" entrana la incorporación de una constelación de principios, en el sentido fuerte del término. Si estos "nuevos" principios resultan equiparables epistémicamente a los establecidos racionalmente, la noción de ciencia resulta afectada en la medida en que sus aparatos "demostrativos" vengan dialécticamente determinados por el juego argumental derivado de la presencia de dichos "principios" de fe. La controversia entre "verdades de fe" y "verdades de razón" no es más que la afloración del conflicto entre principios incompatibles. 
principios y fundamentos. Tomás de Aquino hizo un comentario a la Fisica que tuvo muchos seguidores hasta el Renacimiento. Cuando comenta el texto (2) que hemos citado más arriba dice: (4)

" Dicit ergo primo quod non pertinet ad scientiam naturalem intendere ad perscrutandum de hac opinione, si ens est unum et inmobile. Jam enim ostensum est quod non differt secundum intentionem antiquorum philosophorum, ponere unum principium inmobile et ponere unum ens inmobile"18.

Esta lectura de T. de Aquino introduce algo que no está en el texto: la inmovilidad del principio - el texto solo menciona la del ente-, propiedad que solo tiene sentido del principio si implícitamente se supone (como Aristóteles atribuye a Parménides y Meliso) que se habla de un principio ontológico (Dios, para los teólogos ${ }^{19}$ ). ¿Cómo iba a ser Dios o su inmutabilidad un tema de la Fisica. A la vez, elimina del texto el distanciamiento que quizá fuese la intención principal de Aristóteles, porque solo toma en cuenta la correla-

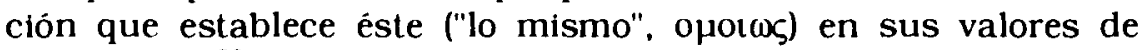
coincidencia ${ }^{20}$.

${ }^{18}$ Th.de Aquino: In Octo Libros Physicorum Aristotelis Expositio. Lb.I.Lect.2; 15. Edt. Marietti. Turin 1954.

19 Quizá pueda sospechar el lector que mencionar a Dios resulta excesivo aqui. Pero podriamos recordar que el propio Th. de Aquino lo hace explicitamente muy poco antes de este punto; en efecto. cuando interpreta el primer párrafo de la Fisicael que introduce la idea de "ciencia"- nos presenta el cuadro de los seres que son objeto de ciencia en relación con lo que suele denominarse "grados de abstracción" de la materia: " Guactam vero sunt quae non dependent a materia nec secundum esse nec sccundum rationem; vel quia numquam sunt in materia. ut Deus et aliae substantiae separatae; vel quia non universaliter sunt in materia, ut substantia. potentia et actus, et ipsum ens." El ente y Dios se hallan, pues, en el mismo "grado de abstracción" y. por tanto, en el mismo rango epistémico. Confr. 1.c. 1,2,2.

20 Th. de Arjuino habia dejado establecido, al comentar el "buscan lo mismo" que: " Deinde cum dicit: similiter autem querunt etc. ostendit quod eadem diversitas opinionum est circa entia.

Et dicit quod similiter physici, inquirentes de iis quae sunt, idest de entibus. quaerunt quot sint, utrum scilicet unum aut plura; et si sint multa, utrum sint finita vel infinita.

Et ratio huius est. quia antiqui physici non cognoverunt nisi causam materialem. de alis autem causis parum tetigerunt. Ponebant autem formas naturales esse 
Pero, volviendo al texto (2), hacer lo mismo puede significar (y traducirse) con varios sentidos. En el más fuerte posible significaria hacer la misma cosa de la misma manera, y es obvio que tal lectura seria poco sensible al carácter comparativo de ouoíws y que tiende a interpretar este término como término de identidad, sin fundamento lingüístico ni contextual. Esto es lo que, según creo, hizo Tomás de Aquino.

Otras dos lecturas, en realidad paralelas, podrian ser: hacer la misma cosa de distinta manera y hacer distinta cosa de igual manera. El texto de Aristóteles parece sugerir más bien alguna de estas dos lecturas; la primera se fija más en la coincidencia que parece darse en lo buscado (mencionado en los dos términos de la comparación de $<2>$ ):

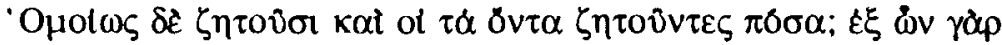

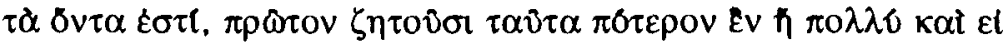

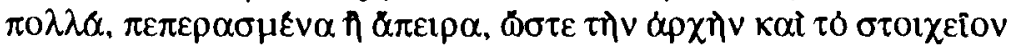
$\zeta \eta \tau 0 v 01 \pi \delta \tau \varepsilon \rho \circ \vee \varepsilon \vee \eta \pi \mathrm{N} \lambda \lambda \alpha$.

En suma:

i) Similar ${ }^{21}$ es la investigación de quienes buscan cuántos son los entes ii) Pues al estar las cosas existentes constituidas de

accidentia, sicut et artificiales: sicut ergo tota substantia artificialium est eorum materia. ita sequebatur secundum eos quod tota substantia naturalium esse eorum materia.

Unde qui ponebant tantum unum principium, puta aërem, putabant quod alia entia essent aër secundum suam substantiamet simile est de aliis opinionibus. Et hoc est quod dicit, quod physici quaerunt ex quibus sunt quae sunt: idest. inquirendo de principiis inquirunt causas materiales, ex quibus entia esse dicuntur. Unde patet quod quando inquirunt de entibus, utrum sint unum aut plura, eorum inquisitio est de principiis materialibus. quae elementa dicuntur". L.c. I,1,2,14. $\quad$ E s bastante lejano respecto al texto aristotélico lo que T. de Aquino "interpreta" como sentido del texto que comenta. El lector juzgará.

21 En (a) omoios equivale a "siniliter": en (b) equivale a "non aliter". El comentario de Th. de Aquino ya lo hemos ofrecido en la nota anterior. Veamos el de los conimbricenses:" Non aliter inquirunt. Varie hunc locum explicant Alexander.Simplicius et Averroes. Videtur tamen significasse Aristoteles hanc, quam sequitur, philosophandi rationem. scrutando nimirum Physicarum rerum principia. nequaquam novam esse, cum cam alii ante ipsum usurparint: qui cum eorum. quibus universitas constat, numerum, seu multitudinem investigarent, re ipsa nihil aliud, quam quot essent renum initia disquirebant". Confr. L.e. pg. 81-82. 
ellos,iii) Se empieza por investigar si son uno o muchos y, si muchos,en número finito o infinito. iv) Al igual que los que buscan del principio y elemento <empiezan por investigar si es uno o múltiple ${ }^{22}$.

De este modo en la segunda lectura - de las dos paralelas propuestas- del texto parece que la coincidencia se desplaza de lo buscado ( de la coincidencia entre buscar principios y buscar entes) a la categoria conceptual desde la que se busca: (coincidencia en buscar si uno o múltiple). Y ello haria inclinar la interpretación hacia la ültima de las lecturas propuestas.

Me inclino por la idea de que Aristóteles sigue alguno de estos hilos argumentales porque continúa su texto afirmando, o quizá excluyendo una de las alternativas : <pero> "escudriñar si el ente es uno e inmóvil no es escudriñar sobre fisica ${ }^{23 "}$, de lo que se seguiria que, si êl investiga aqui sobre physica, no investigará sobre si el ente es uno e inmóvil, y por eso sigue razonando sobre la necesidad de una ciencia común a todas, $\pi \alpha \sigma \omega ె v$ kotvis. En consecuencia las primordiales investigaciones fisicas, $\tau \delta$ $\pi \varepsilon p i \phi v i \sigma \varepsilon \omega \zeta$ $\sigma \kappa о \pi \varepsilon n$, adquieren para Aristóteles un nivel dependiente o

22 Para ilustrar esta interpretación transcribo las traducciones de este texto en (a) y (b):

(a) "Similiter autem quacrunt et quae sunt quaerentes quot sunt. Ex quibus enim sunt quae sunt querunt primum, utrum haec unum aut plura sint: et si multa, aut finita aut infinita. Guare principtum et elementum quaerunt, utrum unum aut multa."

(b)"Non aliter inquirunt, qui ea quae sunt quot sint scrutantur. Nam de his primum quaerunt e quibus sunt entia, utrum unum an plura: et si plura an finita, an infinita. Guare inquirunt an principium unum sit. an multa."

23 De nuevo surge aqui una perplejidad en la lectura del texto aristotélico: contraponiendo una pregunta a la afinmación del Estagirita ¿es una investigación fisica investigar si los principios son uno o mültiples. móviles o inmóviles? si lo fuera ¿qué fisica seria ella, o en qué distinta de la presocrática? y si no lo fuera ¿qué clase de investigación traeriamos entre manos?. Obviamente estas preguntas solo se pueden hacer post-aristotélicamente. Tras la cuestión de la unidad y multiplicidad del ente hay que ver la argumentación de Zenon y de Meliso. Tras la unidad o pluralidad de principios y elementos hay que ver a Empédocles, Anaxágoras. Espeusipo y los pitagóricos y los atomistas, todo lo cual tiene más que ver con la idea arcaica de physis que con la idea de ciencia natural . 
conectado con otras investigaciones cuyo método ${ }^{24}$ parece aludido aquí y cuyo objeto incluye al menos el estudio de conceptos tales como la unidad o pluralidad, la movilidad o inmovilidad etc. Pero, ¿para qué serian necesarias semejantes elucidaciones sobre los principios, las causas y los elementos?.

\section{Cómo vencer dialécticamente a Parménides o lo que no sabia hacer Platón.}

Todavia nos encontramos en el segundo capitulo con otro texto intrigante:

(4)

Por nuestra parte damos por supuesto ( $\delta \pi \circ \kappa \varepsilon f \sigma \theta \omega)$ que por naturaleza ( $\phi \sigma \sigma \varepsilon 1)$ o todo o algo es movido ( $\pi \pi \alpha v \tau \alpha \hbar \varepsilon v i \alpha$

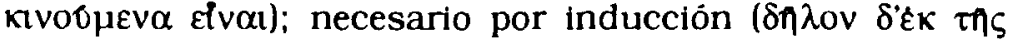
$\varepsilon \pi \alpha \gamma(\omega) M S)$. Y además de nada en absoluto sirve resolver todas las dificultades, sino solo aquellas que llevan a error a quien parte de principios ${ }^{25}$.

El primer resultado a que llevaria la introducción de una ciencia común que investigase los principios, causas y elementos parece que permitiria abordar los estudios fisicos desde un supuesto que incluye dos afirmaciones: i) existe movimiento o estado de movimiento. ii) algo o todo existe y se halla en ese estado. Pudiera pensarse que estas afirmaciones irian destinadas a los eléatas por la presencia de los nombres de Parménides y Meliso en el texto. No

\footnotetext{
${ }^{24}$ Aristóteles vincula este análisis con la discusión dialéctica tamizada por el correcto uso de los términos y de las premisas. Parece pensar en la silogistica, que habria que suponer ya configurada en el momento de redactar este Lb I, como el

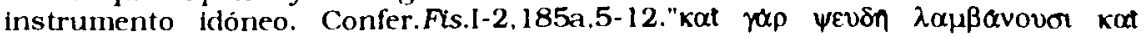

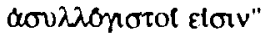

25 Fis. 1-2, 185a, 12-15. Respecto al lugar que la Epagogé debe ocupar en la organización de los métodos que utiliza Aristóteles para alcanzar "principios". es preciso recordar que. en muchas ocasiones, se asienta en lo que denomina kvobogov, que puede entenderse como "opinión común", "opinión aceptada". etc. lo cual remite el problema al estado de opinión respecto a las diferentes cuestiones. Este estado de opinión, sin duda, tendria más que ver con las disputas académicas que con la mera opinión pública. Respecto a la última afirmación hay que sopesar el valor de "argumentar desde principlos" \& quiénes argumentaban falsamente desde principios? Explicitamente Zenon. Cfr. J.Burnet. 1970. pg 352.
} 
seria nada extraño que frente a ellos se proponga como una tesis dialéctica, aunque llama la atención del lector, que semejante "supuesto" signifique dar por sentada en una instancia anterior la cuestión parmenídea. ¿Cómo y cuándo?. Cuando se hubiere regresado dialécticamente a esa "ciencia común". Salvo que quizá, tras esta primera intención, bien pudiera entreverse una segunda: una crítica severa ${ }^{26}$ y una revisión aristotélica de los Diálogos platónicos de asunto eleático. Diálogos que no habrian logrado romper el continuo argumental parmenídeo ( de Zenón y Meliso, principalmente) entre ente y physis, y que es el que aqui se quiere romper con la hipótesis propuesta. Porque, ¿qué significa aquí una epagogé como garantia de un supuesto tan fuerte? Lo primero que indica es que se remite la discusión sobre la unidad o la pluralidad del ente (temas del Parménides) desde el comienzo de la fisica hacia otra investigación anterior o "ciencia". Lo segundo es que se fija, o se da por fijado, para la física un ámbito inicialmente definido : el movimiento de un todo ${ }^{27} \mathrm{o}$, al menos, el de las cosas singulares contenidas en él. Lo tercero es que parece quedar delimitado, mediante este supuesto, el tránsito desde la ciencia común a la ciencia fisica. Finalmente nos indicaria que la elucidación debida a la epagogé es anterior, metodológicamente, al supuesto inicial y que ha ocurrido o debido ocurrir en un análisis anterior o superior.

26 Cuánto de critica y cuánto de burla hay en el fanoso texto " Guerer demostrar que las cosas naturales existen. es ridiculo. pues eso lo estamos viendo. Quien intenta explicar algo que existe manifiestamente por medio de algo invisible. revela su incapacidad para distinguir lo evidente por sí mismo de lo que necesita una explicación. Asi, alguien que fuera ciego de nacimiento podria sacar muy ingeniosas conclusiones acerca de los colores, pero tales discursos no dejarian de ser sino palabras, en las que no se piensa nada". Phys.II.193a.5 sts.

27 J.Burnet hace una observación sumamente interesante: "los procesos de nacimiento, crecimiento y destrucción, podian considerarse como actividad incesante de la única y última realidad. Aristóteles y sus sucesores expresaron esto diciendo que los primeros cosmólogos creian en un movimiento eterno y en conjunto esto es verdad. si bien, muy probablemente ellos en sus escritos nunca hayan dicho nada sobre movimientos eternos. Mucho más probable es que lo tomasen por un hecho. En los tiempos primitivos, no es el movimiento, sino el reposo lo que requiere explicación, y podemos estar seguros de que la etemidad del movimiento jamás fue afirmada antes de ser negada. Y. como veremos. fue Parménides el primero en negarlo." Cfr. Burnet L.c. pg. 15. 
quizá un análisis perteneciente a la ciencia común a todas las ciencias, en donde hallaria su justificación.

Convendrá aqui mencionar la dificultad que encierra el uso de epagogé como mecanismo para establecer el punto de partida de una investigación. En algunos contextos Aristóteles usa este término con la aparente significación de alcanzar principios de una ciencia a partir de los datos de la percepción ${ }^{28}$. Pero en otras ocasiones parece reservar el término para nombrar a uno de los dos métodos fundamentales de la dialéctica ${ }^{29}$ partiendo de opiniones comúnmente aceptadas o de "usos" naturales del idioma (si no "naturales" en un sentido esencialista, al menos en un sentido "naturalista" acorde con su idea de physis) y llegar asi a establecer principios, aceptados comúnmente, para las ciencias ${ }^{30}$.

Una vez establecido el supuesto básico. parece que Aristóteles habria de abordar problemas de movimiento en el sentido en que usamos el término hoy: pero, lejos de ello, se vuelve sobre cuestiones presentes en la discusión platónica con los eléatas y otras escuelas antiguas (aunque también sobre los propios planteamientos de Platón y de Espeusipol como si el objetivo fuese ahora probar la consistencia de la hipótesis debida a la epagogé, y ello mediante argumentos y distinciones que debieron ocupar mucho tiempo en sus dias de Academia ${ }^{31}$ y que surten a la Fisica de términos, de paradojas, de reformulaciones de conceptos, etc, como si se tratase de unos apuntes destinados a reescribir el Parménides y el Sofista. al igual que partes del De Caelo parecen destinadas a una reescri-

${ }^{28}$ Así p.e. en An.Post. I 18.81 a 38-b9; Il 19,100b 3-5

29 Como en Topic.I 12,105a 10-19.

${ }^{30}$ Esto parece ser lo que quiere decir en Topic.l 2.101a.36 y 101b.4.En otros lugares parece menos seguro el uso del término.p.e. en Fis.V.5.229b.2-3,dice: "es evidente por epagogé cuales parecen ser los contrarios" lentre términos del cambio o metabolé). En este pasaje, a tenor de los ejemplos que propone, la epagogé vendria a consistir en el análisis completo de cada térnino y de sus posibles "contrarios" lingüisticos, una especie de lista completa de antónimos.

31 Me parece oportuno llamar la atención sobre el hecho de que en este Libro I. en los Cps. 8-9 ( si es que fuesen de época muy temprana) aparecen ya los elementos artstotélicos que dan pie a elaboraciones posteriores: dynamis y energeya.Cfr. $191 \mathrm{~b}, 27$ y stss. que son conceptos presentes por igual en el Libro "lambda" de Metafisica. 
tura del Timeo. En tal caso habria que poner en relación el término "physiké" de Aristóteles, al menos aqui, con el valor que exactamente hubiera de tener el término "Physis" en el poema de Parménides Peri Physeos. Además, Platón habia introducido a un "Aristóteles" en el Parménides con el pretexto de que "era el más joven" de los presentes y le correspondía presentar por los demás las objeciones a Parménides. ¿Podía estar Aristóteles satisfecho con los argumentos cruzados entre el Parménides del Diálogo y el Aristóteles contrapuesto por Platón?. No, a buen seguro. En todo caso estos son meros indicios, y arguyen en favor de la conjetura de que el primer Aristóteles asume los problemas filosóficos de la Academia, tanto si se entienden como disputas, ya internas ya "ad extra", como si se entienden en su forma social o "publicada"32.

\section{Fisica o Fisiologia. Demasiada Physis.}

El hecho es que los contenidos de los ocho libros de la Fisica ${ }^{33}$ tienen aparentemente poco que ver con lo que habria de ser una ciencia subsiguiente a una hipótesis como la aceptada, aún para el propio Aristóteles, y menos aún con lo que hoy entendemos por ciencia fisica. Es, más que un indicio, un argumento significativo su definición de physis:

(5)

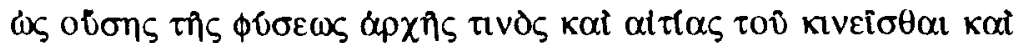

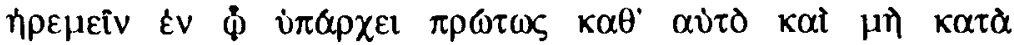
$\sigma u \mu \beta \varepsilon \beta \eta \kappa \delta \zeta$. "de modo que naturaleza es principio y causa de estar en movimiento y en reposo para algo, en lo cual está primordialmente en cuanto tal y no por accidente $\mathrm{e}^{\mathrm{n} 34}$

Pocas lineas más adelante vuelve a afirmar que "physis es lo que acabamos de decir" con ejemplos como "que el fuego se mueva

\footnotetext{
32 Para ver casos concretos de correspondencia entre los temas y argumentos de la Fisica y del Parménides vide:Allan.D.J.: The Phulosophy of Aristotle.Oxford U.Press 1970. Y Owen.G.E.L. "Tithenai ta Phainomena" en Aristote et les problèmes de methode. ed. por S.Mansion.Lovaina la nueva. 1961.

33 No insistiré en las distancias temáticas, cronológicas y de otros tipos que separan los contendlos de la Fisica. Más bien las doy por supuestas.

${ }^{34}$ Phys. 11. 192b,20-23.
} 
hacia arriba no es "naturaleza = physis, sino por naturaleza = physei". Cada vez que aparece un ejemplo, caso o fenómeno, no es utilizado para ser explicado en sí mismo o en el contexto establecido por la hipótesis aceptada. sino como auxiliar de una argumentación $^{35}$ abstracta sobre conceptos y sobre definiciones que "tienen historia" filosófica, historia vinculada a la larga tradición, reelaborada minuciosamente por él mismo, de las formulaciones sobre la physis $^{36}$ que, antes que del movimiento perceptible, es origen de cuanto aparece y desaparece, de cuanto es y deja de ser: la gran cuestión de cualquier pregunta por el mundo, que lo era primordialmente de los presocráticos ${ }^{37}$. La pregunta por la physis era la pregunta radical, al menos hasta Sócrates, porque tras ella los griegos percibian la pregunta por "la totalidad". Como objeto de una ciencia es evidentemente demasiado preguntar, pero Aristóteles no parece que se arredrara, antes al contrario, por dicha demasia.

35 Para decirlo con las propias palabras de Aristóteles: "La comprobación es un argumento más convincente y claro, más accesible a la sensación y común a la mayoria. mientras que el razonamiento es más fuerte y más efectivo frente a los contradictores" Tópicos. I, 12.105a.17-19.

36 La concisión de las definiciones aristotélicas es célebre. El lector puede hallar muchas, aunque me pernito destacar la de physis en tanto que "materia": "En un cierto sentido se llama physis a la materia primera subyacente a cada cosa de las que tienen en sí mismas principio de movimiento y cambio" Phys. II. 193a,28-29. El

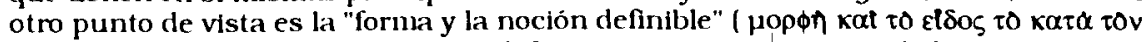
hoyov). Tras el análisis de estas dos definiciones contrapuestas y de los argumentos en pro y en contra dice algo sorprendente: "A quien vuelva la vista a los antiguos le pareccria que <el tema de la fisica> es la materia" (194a. 18-19). Pero este discurso concluye con una afimnación de su punto de vista que merece destacarse: "En las cosas artificiales ponemos la materia con vistas a la forma, pero en las naturales <la materia> subyace a cada una. Además. la materia es un relativo: pues a otra forma, otra materia.... pues. cada cosa tiene su para qué y de cada una de ellas es separable la forma, pero en una materia. El hombre, más el sol. engendra al hombre. Es tarea de la filosofia primera detenninar cómo tiene lo separado y el qué es". Ibd. $194 \mathrm{~b} .4$ y stss.

37 Creo que J. Burnet lo expresa correctamente: En su introducción trata de fijar el valor de PHYSIS y dice: "Que yo sepa ningün historiador de la flosofia griega ha establecido janás claramente que la palabra empleada por los antiguos cosmologos para expresar esta idea de una sustancia permanente y primordial no era otra que la palabra physis . y que el titulo peri physeos. tan frecuentemente otorgado a las obras filosóficas de los siglos VI y V a.C. significaban puramente: "Sobre la sustancia primordial" .... en el lenguaje filosófico griego physis denota siempre aquello que es primario. fundamental y persistente, por oposición a lo que es secundario. derivado y transitorio" (trad. nuestra). Confr. J. Burnet. 1970 pgs. 12-13. 
El lector moderno se sorprende al encontrar, en una disquisición pretendidamente "fisica", discusiones de problemas parmenídeos como el de la "significación única del ser"38, como si la cuestión central a investigar y a proponer fuese que ninguna ciencia de la naturaleza puede construirse sin deshacerse de los prejuicios inmovilistas de los eléatas, prejuicios que, por su parte, tampoco Platón habria logrado desmantelar, en opinión de Aristóteles. La crítica necesaria para ello procede de una reconsideración de todos los elementos implicados en la argumentación parmenidea ${ }^{39}$. pero también en los recursos dialécticos idóneos. Aristóteles muestra que la lógica de Parménides falla porque éste no distingue entre los sentidos del término "ser": no ha logrado comprender que $\delta v$ se dice $\pi 0 \lambda \lambda \alpha \chi \omega \hat{c}$. No podemos saber hasta qué punto estas cuestiones heredadas, no solo vía Platón, entorpecieron y hasta desorientaron a Aristóteles cuando se vio inmerso en ellas. La tarea de sacar a la ciencia de la naturaleza de los atascos aporéticos en que la habian sumergido sus primeros cultivadores no hubiera resultado nada fácil tampoco de haber continuado Aristóteles por la via de los fisicistas jonios. Las críticas que hace a sus diferentes planteamientos ${ }^{40}$ no parecen indicar especial simpatia hacia métodos observacionales. El análisis de términos, de sentidos posibles e imposibles, de contradicciones y falacias (dialéctica al fin y al cabo) detiene la investigación en los confines del lenguaje, o más exactamente, dentro de los limites

38 Véase Fus. I,3. 186a,32 y stss. donde analiza las consecuencias de la idea parmenidea de que cl ser tenga significación única. (on semainein en)

39 No puedo ocultar mi sospecha sobre este punto. Zenon y Meliso (por razones que ignorol parecen ser los eléatas principales, los más inmediatos y los más directos representantes de su viejo maestro. Los escritos de uno y otro circularian en la Academia como representantes del pensamlento de Parménides y en forma argumental, no poética. como los de su maestro. Por tanto el eleatismo era de hecho el de Zenón y el de Meliso, a efectos argumentales. Por ello en térninos argumentales les responde Aristóteles. La distinción entre entes, por un lado. y principios, causas y elementos, por otro, debe tener su origen en este empeño aristotélico por desmontar sus argumentos. Por otra parte, aunque a Zenón atribuye Aristóteles la paternidad de la Dialéctica. ni a él ni a Meliso les profesó mucha consideración. Confer. J.Burnet. 1970 . Pgs. 359 y 372 respectivamente.

40 Aunque son muchas y desde diferentes perspectivas, véase la que pertenece al contexto a que nos referimos en Fis $1,5.186 b, 26$ y stss. pero resultan excesivamente vinculadas al análisis que hizo antes desde una perspectiva terminológica. 
dialécticos que Aristóteles puede elaborar para ese lenguaje. Y este me parece un indicio muy significativo del interlocutor principal a quien se dirigia Aristóteles: la exposición (hoy la llamariamos "escapista") que de las cuestiones filosóficas se venia haciendo en la Academia. Aunque el momento en que Aristóteles redactó estos esbozos argumentales no parece seguro ni para la totalidad del texto ni para cada parte del mismo, resulta muy probable que el interlocutor inmediato de su discusión sea el círculo platónico de la Academia de los años 360-50 (a.c.) con el que convivió y al que no llegó a dirigir como escolarca, pero de cuya problemática se hace heredero y crítico a la vez. El Lyceo posterior ( o donde enseñara Aristóteles en su segunda estancia en Atenas) siguió manteniendo vivas muchas de las cuestiones de la Academia y también las reformuló, quizá para no desmerecer ante la opinión, para mantenerse a la altura a que estuvo la escuela platónica y para granjearse la aceptación ateniense, en medio de los recelos antimacedonios. El caso es que los problemas sobre la physis habian sido en el pasado inmediato problemas familiares a la cultura filosófica griega, de manera particular en la Academia. El tiempo de estancia de Aristóteles en ella debió determinar el carácter de sus investigaciones filosóficas iniciales sobre estos problemas, tanto en la forma como en el contenido mismo de su discurso, a la vez que debió ser el momento en que redactó los núcleos principales de los textos que aqui nos ocupan. Su marcha. sus viajes por Asia Menor y Macedonia y su encuentro con Theofrasto debieron influir en la orientación posterior.

Todas estas conjeturas, aunque cargadas de probabilismo sociológico, deberian servir para situar los esfuerzos aristotélicos por fundar una ciencia de la physis en la perspectiva en que se

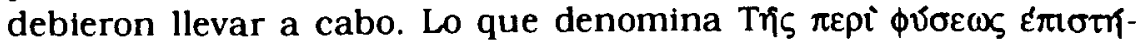
$\mu m \varsigma^{41}$, tal como nos ha llegado a nosotros, tiene demasiados objetos de estudio y por ello se puede decir que es un agrupamiento de discusiones, más que una ciencia de la naturaleza: el estudio se hace desde categorias demasiado generales (ciertamente codificadas por él mismo como garantía en la dialéctica del razonamiento o de la demostración), por lo que escasamente se desciende al análisis

${ }^{41}$ Como en Fis. I. 184a, 15 ;VII.250b, 16:De Caelo I.208a.1. 
de los fenómenos concretos de modo inmediato, y esta es una caracteristica esencial de estos escritos que los aparta de lo que hace normalmente cuando, más tarde, quiere hacer ciencia, como hace p.e. al estudiar la vida o el reino animal: empieza por hacer "historia de..", descripción y anālisis del objeto a estudiar. Dicho escuetamente, se mantiene en cuestiones de elucidación conceptual de principios. Pero, al tratarse de principios de la physis como "todo", resultarán siempre análisis de lo más general, y esto solo en un sentido puramente dialéctico y peculiar del momento puede ser interpretado como "perteneciente a la Fisica". Para decirlo crudamente, no se sabe de los médicos, ni de las comadronas, ni siquiera de los escultores que hacian "estatuas de bronce" que preguntasen a Parménides sobre la posibilidad de hacer lo que hacian. ¿Por qué habria de hacerlo Aristóteles para hacer investigaciones fisicas?. Salvo que no hiciese exactamente investigaciones fisicas en este momento, y entonces hubiese de atenerse a otra regla de juego.

\section{La Dialéctica peculiar de Aristóteles.}

Los términos generales susceptibles de nombrar lo más común y lo más abstracto son los elegidos por Aristóteles para su anâlisis fundamental. Es, en suma, un esfuerzo riguroso para depurar los valores y usos de términos comunes implicados por el lenguaje culto en los discursos sobre la naturaleza. Pero, ¿cuales son los criterios para alcanzar su objetivo?. Continuamente apela al uso argumental de las definiciones de términos usuales (armónico e inarmónico, blanco y negro, etc) como via mediata o inmediata para llegar a principios, causas y elementos, objetivos últimos de su análisis. Pero tampoco estos términos son ajenos a la evoluciôn de sus diferentes sentidos en cada contexto. Y , aparentemente, el contexto de las discusiones arcaicas sobre la physis es el que determina inicialmente el uso "bueno" o "malo" de esos términos y de sus definiciones. Como Aristóteles se ve en la necesidad de analizar estos valores de uso (cosa que no deja de ser una "epagogé"), de paso se ve envuelto en esa misma tradición filosófica, sobre 
todo tal y como esta habia sido comprendida en la Academia ${ }^{42}$. Por esta razón su idea de ciencia explicativa se dinge hacia la fundamentación de estos elementos conceptuales ofrecidos por la tradición dentro del contexto en que los ha transmitido esa misma tradición ${ }^{43}$. Con ello, evidentemente, sigue dentro de ella, con mayor rigor y precisión, tal vez, pero sin efectuar una ruptura conceptual, lo que hoy llamariamos una revolución. En otras palabras, ni el objeto de su ciencia ni los fundamentos que investiga para ella son revolucionarios.

$Y$ sin embargo, no resulta menos evidente que los textos de Aristóteles, aunque debatan viejos y arcaicos problemas incluso para su tiempo, parecen pertenecer a un modo de discurrir muy diferente de los de sus predecesores, no solo por su precisión en las distinciones, sino por el hecho de que razona mediante términos cuyas referencias han sido establecidas con gran precisión. Otra cosa es que esas referencias establecidas con gran cuidado fuesen las adecuadas en cada caso (como ocurre en los Lb.V y VI de la Fisica con el análisis temporal del movimiento, donde se expresa como si nunca hubiese observado con detenimiento fenómenos de aceleración y desaceleración en su entorno ${ }^{44}$ ). No obstante, la

\footnotetext{
42 Un ejemplo muy ilustrativo lo hallamos en el De Caelo I.3.270b. 16 y stss. donde Aristóteles analiza el sentido heredado del término "eter" y las razones de su signiflcado entre los antiguos, de los que descarta a Anaxágoras.

43 Puede verse, como ejemplo de esto que vengo comentando, su tratamiento de la "teoria de los contrarios" como principios de la generación, en Lib. I. cap.5 (188a.19 y stss.), o en el cap. 7 cuando explica su teoria de la generación contraponiendo expresiones del tipo "el hombre culto se engendra a partir del hombre inculto" o la "estatua se genera (procede) del bronce" y no "el bronce se hace estatua", etc.

44 A veces se ha querido ver en Fis. VI,2.232a,23 y stss. cierta aproximación a la idea de aceleración. Pero el problema central es aqui el de la divisibilidad del continuo (espacial o temporal).En el fondo se trata de analizar qué ocurre si a una sucesión temporal continua y única se le superponen dos movimientos continuos distintos (el de Aquiles y el de la tortuga) y si cada subdivisión del continuo temporal se proyecta sobre los otros dos continuos móviles \& se anula el tiempo a base de divisiones? Como ya ha demostrado que la respuesta es "No", entonces mientras haya tiempo habrá movinientos y además distintos en velocidad para cada partícula igual de tiempo. Esta es la relación de proporcionalidad paralela y directa que discute Aristóteles y por eso la conclusión lleva a una refutación más de Zenón ,poco más adelante en 233a. 21 y stss. aunque después, in extenso. le dedique buena parte del VI.9, 239b.5 y stss.
} 
forma aristotélica del discurso científico impregna a este de un modo tan decisivo que consagra para siglos sus arcaismos cientificos, y bloquea muchos desarrollos que pudieran haber sobrevenido más tempranamente. Quizá el mejor ejemplo de esto es el estudio (en buena medida autónomo e independiente de los dos Libros anteriores, aunque no de espaldas a ellos) de la idea de movimiento desde el Libro III de la Fisica, estudio que tiene sus raices claras en el estudio platónico, en su análisis del pensamiento eleático, y que tampoco cambia de perspectiva en los Lbs. V y VI. Pero el discurso aristotélico difiere del platónico en algo más que en los términos. Se suele hacer hincapié en que Platón hace referir los términos a las Ideas, mientras Aristóteles los hace referir a las cosas, pero es preciso no olvidar que esto se hace mediante una concepción implícita del lenguaje como signo natural inmediato de esas mismas cosas. Con gran frecuencia argumenta, a favor o en contra de alguna tesis, con un "se dice" o " no se dice" tanto para definir el uso común de un término como para definir el uso propio del mismo ${ }^{45}$. El resultado de estos análisis no siempre acaba en una buena distinción, aunque ésta resultare precisa, sino que al final desagua frecuentemente en una imaginativa trivialidad ${ }^{46}$, o en una afirmación razonada con esmero de una tesis común ("la derecha es mejor que la izquierda") de una cultura que nadie ponia en cuestión.

Por lo general se tiende a atribuir a Aristóteles un realismo relacionado con su idea del tơ $\pi$ ơ eival; no estaria yo en desa-

45 De este análisis se pueden dar muchos ejemplos. Remito a uno en que se puede observar tanto la carencia de nombre a usar como la adaptación de alguno de los que se dispone en el lenguaje ordinario. Confer. Fis. V,2,226a 29 y stss. "Respecto al movimiento según la cantidad no hay nombre que designe al conjunto. pero en relación a los dos contrarios. (el nombre es) crecimiento y merma. crecimiento hacia la magnitud completa, merma desde esta"...(tampoco tiene nombre el movimiento en cuanto al lugar) y la palabra "traslado". forá, es introducida con precisiones. etc. En general las precisiones terminológicas parten del reconocimiento de la ambigüedad de un término que Aristóteles subraya con la expresión legetai pollajos o pollajos legomen.p.e. en Fis. V,4,227b 3, etc

46 Tras la famosa definición de "lugar" en Fis. IV,4,212a,20, donde establece que

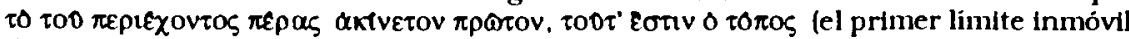
de lo contenido esto es el lugar), aparecen consecuencias como las de los lugares naturales. de la tierra rodeada de agua y esta de aire y este de eter y este de cielo y este de nada. del reposo natural de cada cosa en su lugar propio. etc. 
cuerdo con esta atribución, pero, en mi opinión, el valor del ț no depende en Aristóteles tanto de la experiencia, de la observación. de la experimentación, (aunque no le sean completamente ajenas) como de la correcta asignación de significado a través del análisis de los usos de esos términos, compatibles e incompatibles entre si y con otros, competencia lingüistica que también formaba parte de su idea de empeiria. Esto, una vez más. me lleva a creer que su idea de ciencia (al menos en la época de la Academia) tiene su punto de partida y su "lugar natural" en la dialéctica más que en la fundamentación racional de la experiencia. Y por lo tanto, tiene más de reinterpretadora de nociones comunes con fines argumentales que de heuristica, cosa que se halla en el fondo de los bloqueos que supuso para el futuro. Este carácter reinterpretador propio de la inicial teoria aristotélica de la ciencia produce una fijación a todas luces indeseable, puesto que a un lenguaje rigurosamente construido asocia cast indisolublemente una multitud de seudoproblemas que así permanecen enmascarados. La fuerte argumentación aristotélica es dificil de deshilvanar, tejida como está sobre una base lingüistica dedicada al análisis de lo puramente verbal, y será necesario acumular evidencias empiricas que permitan desligar los términos analizados de los significados fijados por él con tanto empeño.

\section{De la Dialéctica aristotélica al discurso analítico de la ciencia.}

No contribuyó tanto, pues, esta primera parte de la Fisica a la ciencia como al estilo de la ciencia, y sobre todo no estableció los fundamentos de la ciencia tanto como los fundamentos del modelo de discurso científico. El ensayo general de este discurso aparece en ciertos momentos de la Fisica de modo más claro que en otros textos, (quizá con la salvedad de algunas lecturas "intencionadas"de los Segundos Analiticos, aunque aqui sea más bien un metadiscurso) y precisamente en relación con los "principios,causas y elementos". La investigación que realiza Aristóteles tiene un horizonte retrospectivo en tanto que "principios causas y elementos" son temas arcaicos aceptados por él, aunque con matices importantes, y de ello son testimonio las continuas "refutaciones" que propone de las doctrinas heredadas a través, principalmente, de la Acade- 
mia. El discurso $\delta 1 \alpha \pi$ se construye en oposición al discurso analógico anterior, $\delta \mu 0$ to $\zeta$, con exigencias de rigor totalmente

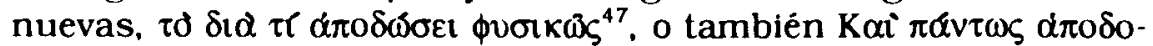
$\tau$ tEov $\tau 0 \delta 1 \alpha \pi^{48}$, y tantos otros ejemplos posibles, en los que aplica a su discurso un esquema explicativo del típico formato $\delta \imath \alpha \tau$, en contraposición clara a quienes apelan a explicaciones del tipo de la "amistad, el odio o la inteligencia"49.

En el Libro III- que abre, sin duda otra investigación- parece abordarse el problema del movimiento, ya que se ofrece el estudio

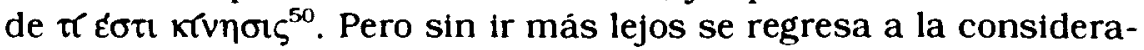
ción del problema y de su formulación aporética en términos

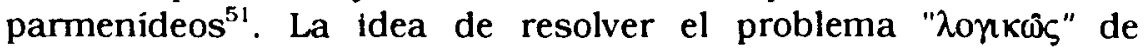

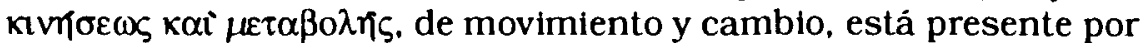
doquier. El esfuerzo conceptual de Aristóteles se apoya en la

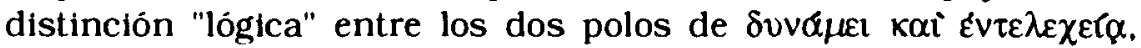
distinción que representa su propio avance sobre la aporia de los eléatas. Otra cosa que ocupó demasiado tiempo y esfuerzo, porque

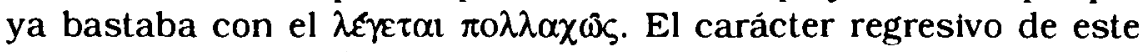
redescubrimiento de los antiguos hace que los análisis sobre conceptos de uso platónico sea recurrente, tal y como si de una reescritura de los mismos se tratara, pero también como si en la

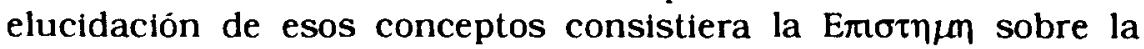
Physis. Por ello la continuación del libro III (por seguir con el ejemplo), desde el cap.4, es un detenido análisis del infinito, porque algunos de quienes le han precedido en el estudio de la naturaleza han considerado al infinito como un principio de los seres ${ }^{52}$. Y este es otro argumento en favor de la tesis que atribuye a Aristóteles

\footnotetext{
47 Fis.II.7. 198a.23.

${ }^{48}$ Id. $198 \mathrm{~b}, 6$.

${ }^{49}$ Como dice explicitamente en Fis.II,8,198b,17. En este pasaje contrapone la bondad de las explicaciones finales a la inanidad de las explicaciones que operan

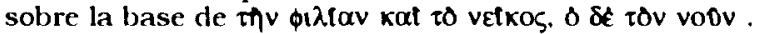

50 Fis. III, 1,200b, 14.

51 Quizá era mejor decir que "regresa" al marco en que primitivamente habia establecido el problema en los escritos que ahora llamamos libros I y II de la Fisica.

52 Fis.III.4.203a.1-4.
} 
una idea arcaica de Physis, aunque no tanto de Episteme, y que reprocha al estagirita el haber bloqueado con su modélica labor redefinidora el desarrollo de la ciencia. A medida que vamos avanzando en la lectura de la Fisica se constata que cada vez el análisis se devuelve una y otra vez a las cuestiones definicionales previas a la cuestión del movimiento. La importancia que adquiere la pura posibilidad de las formas "naturales" de movimiento, en especial la generación y la alteración. frente a la imposibilidad que les atribuyera Parménides, hace del objeto de esta obra un ensayo (o ensayos) deuteroplatónico. Este carácter obligaria a excluir a este tipo de obras (al igual que a sus comentarios medievales más "fieles") de la tradición fundacional de la ciencia. Notemos que el regreso reconstructor de la Fisica lleva por sus pasos a la cuestión del motor inmóvil (sea cual sea el grado de unidad que existiere entre los primeros libros y VII- VIII) y que en esa dirección no hay un mayor conocimiento de la naturaleza. Lo que si hay es una argumentación o un discurso en el que se materializa la idea de "acercarse a la fisica", o "dirigirse hacia la fisica"53 , desde y mediante análisis previos organizados en forma "epistémica", empeño claramente diferente del ideal platónico de " ciencia única". Empeño que, a la larga, determina la noción de análisis textual, primero, y conceptual, más tarde, y que viene a constituir la arqueología misma de la crítica como forma válida de desarrollo del conocimiento. No es esta una de las menores aportaciones de la dialéctica aristotélica.

Ahora bien, cuando se leen detenidamente los argumentos de Aristóteles, sorprende que casi siempre se apoyen en distinciones de valores o de usos de términos. O bien abre su argumento con un

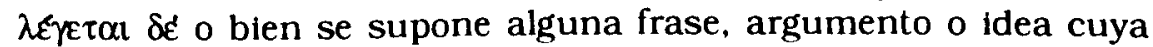
expresión terminológica no le satisface. Y cuando acepta una definición ya circulante no olvida decir que "así lo entiende todo el

53 El texto abre el Lib.III de la Fisic:. "Puesto que la fisis es principio de movimiento y cambio y nuestra indagación va hacia la fisis. es preciso no pasar por

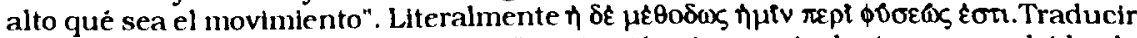
$\mu \varepsilon \theta 0 \delta \omega<$ por "lección" o por "discurso" u otro tẻrmino equivalente parece olvidar lo que quizá era más relevante: la idea de aproximación desde otro lugar (en alguna medicla distinto o alejado) hacia la physis. 
mundo"54. Es caracteristica esta preocupación por el "decir", en consonancia por lo demás con su clásica definición de verdad. Otra cosa es si el procedimiento que utiliza para saber "de lo que es, que es, y de lo que no es, que no es" resultará suficiente. incluso en los casos que pudieran haber sido objeto de alguna comprobación. Y en tales casos todavia se conserva el estilo analítico del uso del lenguaje, de las distinciones y de las contraposiciones ${ }^{55}$. Si no fuera por esto, seria sorprendente, y además contradictorio, que desde una hipótesis o supuesto básico y formulado varias veces explícitamente como el de la existencia del movimiento en la naturaleza se venga a parar en una investigación natural (integrada en la physis) como la del motor inmóvil. Ello obedece al peso de la tradición tanto como al estilo "epistémico" de Aristóteles ( a la postre su intención argumental y dialéctica) y por lo mismo pudiera decirse que, en tanto que autor de estos textos, es aún miembro, aunque disidente. de la Academia. Si Platón "dialoga". Aristóteles "argumenta" y para hacerlo necesita puntos de partida sólidos. Se trata pues de establecer esos puntos de partida y también de establecerlos sólidamente. Hacer esto al modo "aristotélico" requería, más que un decir brillante, un decir coherente, que es la forma en que sospecho que entendió inicialmente la noción de episteme.

\section{Recursos y estrategias nuevas.}

"Conocimiento y sistematización del mismo", eso es la ciencia; mas ahora surge la duda sobre qué sea aquello que es objeto del conocimiento en el caso concreto de la fisica y qué tipo de conocimiento es el que hay que sistematizar y para qué. Más de una vez

\footnotetext{
54 Por ejemplo en De Caelo.li, 3.302a, 14-19. al darnos la definición de elemento.

55 En el análisis extenso de kiveors kaı $\mu \varepsilon \tau \alpha \beta o \lambda \eta$, en Fls. V.4 y 5. p.e.acude continuamente a las categorias de contradicción y contrariedad y analiza hasta la extenuación lingüistica los casos y formas de contrariedad imaginables. El resultado es desalentador y supongo que habria hecho reir a los griegos del tiempo. de haber caido en manos de algún Aristófanes inspirado. Que " el movimiento según la naturaleza es contrario al movimiento contra naturaleza" (Fis. V,6,230b, 14, una de las más brillantes conclusiones) hubiese llenado de admiración y regocijo al griego más iletrado.
} 
dice Aristóteles que eso que hay que conocer son los "principios, causas y elementos" y cualquiera que resulte ser ese conocimiento, este habrá de ser sistematizado según cierto modelo que él mismo

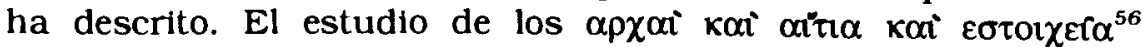
pareceria propuesto como punto de partida para un desenvolvimiento posterior del conocimiento hacia las realidades del mundo móvil y cambiante, como prólogo necesario de las ciencias de la naturaleza. Pero el hecho es muy otro: la investigación recae sobre las condiciones en las que el "conocimiento" de los $\alpha \rho \chi \alpha i$ puede ser considerado como tal conocimiento, esto es, sobre la "logicización" de lo que se dice sobre ese objeto protofísico. Esta "logicización" (recordemos que "logos" es la palabra para la definición y para la conceptualización de algo) no resulta, desde luego, una investigación fisica, por más que algunos temas rocen las cuestiones fisicas del momento. Esta tarea tiene más que ver con una reconstrucción lógica o dialéctica ${ }^{57}$. filosófica en cualquier caso. Porque el problema es básicamente el mismo que aparece planteado, y doxografiado por el propio Aristóteles, en Anaxágoras o Empédocles, Demócrito o Parménides, solo que ahora con nuevas

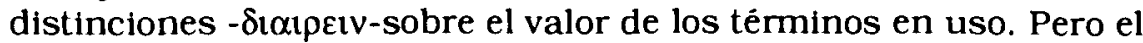
valor de los términos en uso obedece a leyes, en parte lógicas, en parte metodológicas, que obligan a los hablantes a atenerse a ellas so pena de contradicción. Por ello puede argumentar contra Empédocles y otros que "quienes digan cosas como estas (que todo está alternativamente en reposo y en movimiento) no basta que lo digan, sino que han de dar la causa de ello, y nada de suponer cosas ni de formular enunciados sin razón, sino que han de

\footnotetext{
${ }^{56}$ Fis. I,8,102.

57 No se si también esta idea puede extenderse hasta otras obras tales como los tratados sobre los animales. Pero llama poderosamente la atención lo mucho que Aristóteles polemiza con Anaxágoras. Empédocles o Demócrito,p.e. en Sobre la Generación de los Animales. Menciona muchas veces (p. e. en IV.763b,31 y en 769a.7) a otros"fisiologos" con los que discrepa.pero solo nombra a los conocidos. Y si estos "fisiologos" habian desarrollado alguna teoria biológica ¿cuánto hay de investigación propia aristotélica en estos tratados?
} 
proponerse como inducción o como demostración"58. Pero la $\varepsilon \pi \alpha \gamma \omega r \eta$ o la $\alpha \pi \mathrm{o} \varepsilon \varepsilon 1 \xi 1 \zeta$ que recaigan sobre los principios, causas y elementos ya hemos visto que habrian de pertenecer a una ciencia común, ciencia que tal vez hiciera aqui sus primeros ensayos. En algunos pasajes parece que Aristóteles hace uso de claves analiticas codificadas (cuyo resumen pudieran ser los Libros iniciales del Organon) que facilitan notablemente su labor sistematizadora. Pero esta mayor facilidad para el análisis se vuelve contra la exploración ulterior de aquello que está siendo propuesto como problema ${ }^{59}$, toda vez que devuelve a este a su formulación primitiva o heredada, apartándolo de su referencia al mundo. Esto tiene que ver, una vez más, con la concepción aristotélica del lenguaje y del valor del signo "por naturaleza"60. Y añado aqui el entrecomillado para recordar al lector que, (además de la exposición en Analiticos II,19), en el tratado sobre el Alma Aristóteles naturaliza la aparición de "las afecciones del alma" (de los signos mentales que representan a las cosas), exactamente en los términos en que naturaliza las demás formas de movimiento, tales como la generación, etc.. Ello determina la dirección de las investigaciones en el sentido de buscar la compatibilidad de esos signos entre sí, de explicar su presencia en

58 Fis. VIII.1.252a.22-25. Para constatar la presencia de los criterios lógicos en la reconstrucción aristotélica remito al lector a este mismo lugar,pocas lineas más abajo,donde rechaza la justificación propuesta por Demócrito sobre la base de que "siempre ha ocurrido asi".incorrecta para Aristóteles quien objeta que hay que conocer también la causa del "siempre". o de lo contrario valdrá para este o aquel caso, pero no "para todos los casos".

59 Tengo la sospecha.al comparar p.e. Categorias $14.15 \mathrm{~b} .1$ y stss con Fis.V,5,229a,7 y stss. que algunos análisis (en este caso el de las clases de movimiento) se hallan en una relación metodológica casi estricta con las clases de oposición entre térninos(sin olvidar tampoco la renta de esto en De Interpretatione y en Primeros Analíticos). En tal caso la "ciencia común a todas" tendria mucho que. ver con todos los escritos lógicos de Aristóteles.contrapuesta a la retórica más que a la dialéctica.

${ }^{60}$ Recuérdese aqui la presentación que hace en las Categorias, 1, 16a.3-7 : " Así. pues. lo <que hay> en el sonido son símbolos de las afecciones <que hay> en el alma.y la escritura <es simbolo>de lo <que hay> en el sonido. Y, así como las letras no son las mismas para todos, tampoco los sonidos son los mismos. Ahora bien. aquello de lo que esas cosas son signos primordialmente. las afecciones del alma. <son> las mismas para todos, y aquello de lo que estas son semejanzas, las cosas. también <son> las mismas."(trad.Miguel Candel Sanmartin.Tratados de Lógica (Organon) II.Edt.Gredos. Madrid. 1988.pgs.35-36.) 
el alma sin conflicto con el "principio más evidente y necesario" y al que " debe recurrir toda demostración como a última creencia; pues es naturalmente el punto de partida también para todos los demás axiomas" $^{\prime 61}$. Pero esto nos llevaria, entre otras cosas, a una reconsideración muy extensa de textos como Los Tópicos, y en particular del célebre Lib.VI sobre la Definición.

Mi propósito aqui se reduce a un intento previo de esclarecer si la idea de Episteme manejada inicialmente por Artstóteles en la Fisica (que tan grave influencia tuvo tras la recepción de la edición de Andrónico) tiene como horizonte lo que será luego la ciencia alejandrina, p.e. o más bien se orienta sobre lo que sus antecesores consideraron Physis. Si se trata, en suma, de una elaboración fundacional de los conceptos iniciales de una ciencia natural o, por el contrario se trata solo de una reelaboración en términos dialécticos de las especulaciones anteriores sobre un objeto tan amplio como el mundo y su efervescencia. Y mi opción sería más bien ésta última, sin que deje de reconocer determinadas y significativas mejoras aqui y allá en la formulación de aquellos problemas. Pero creo que estariamos lejos de lo que fue el trabajo aristotélico si creyésemos que esas especulaciones reorientaron en algo importante (salvo en lo estrictamente metodológico) a la vieja tradición jonia. No, al menos en cuanto a su dirección global. Sin embargo he mantenido más arriba que hay en ellas un "estilo", cuya vinculación con la "ciencia común a todas" me parece innegable, que surtió efectos notables. Lo diré muy concisamente: en la Fisica no hizo una Episteme, pero intentó aplicar lo que era a la sazón su Epistemologia $^{62}$. La carencia de Escuela ( el Peripato fue fundación

${ }^{61}$ Me refiero a un texto algo extenso que se halla en Metafis. IV.3, 1005b,8-34, en el que Aristóteles discute el principio de no-contradicción mostrando hasta qué punto la afirmación de lo contradictorio es imposible por el hecho de que ello implicaria en el hablante la presencia y la no presencia de una misma creencia en lo que dice.Pero el texto .creo. se entiende mejor si se sustituye "creencia" por "afección del alma".

62 "Aristóteles pregunta siempre dia $t_{乙}$ por qué?, y este método de investigación fue designado más tarde con el término aristotelizein Con su método quiere poner al descubierto los factores que deterninian un cierto proceso y lo conducen a un fin determinado. En este punto. sin embargo, cesa su interés. Jamás plantea la pregunta de si puede verificar la teoria con un experimento o si con base en un análisis se puede predecir el curso de un proceso. La diferencia fundamental entre 
de Theofrasto y con vida efimera), los muy escasos discípulos y amigos ( era un solitario), la casi legendaria e inverosimil recepción de sus escritos inéditos 300 años casi después de su muerte, las circunstancias en que Andrónico hizo su edición ( con el posible efecto arrasador sobre las "obras editadas" que se hallasen en las Bibliotecas de Oriente y que serian suplantadas por la "Nueva Edición $^{63 "}$, etc.) todo esto hizo que la recepción del Aristóteles genuino se convirtiese en una especie de injerto híbrido, el llamado "aristotelismo" contra el que lucha la critica erudita, al menos desde mitad del siglo XIX, no sin éxitos muy notables. A ella debemos la convicción de que las lineas generales de esa epistemologia suelen hallarse en los distintos y dispersos textos conectados con los Segundos Analiticos (aunque estos resulten ser el referente más compacto) debido a la mención expresa que hace Aristóteles en ellos al conocimiento científico mediante demostración. Pero, curiosamente, en el último capítulo niega que pueda darse una ciencia demostrativa de los principios. Por eso la critica moderna considera necesario extender la epistemología aristotélica más allá de los Segundos Analíticos. ¿Hasta dónde?. En el Lib. I de los Tópicos dice: "Pero es que además (la dialéctica) es útil para las cuestiones primordiales propias de cada conocimiento. En efecto, a partir de lo exclusivo de los principios internos al conocimiento en cuestión, es imposible decir nada sobre ellos mismos, puesto que los principios son primeros con respecto a todas las cosas, y por ello es necesario discurrir en torno a ellos a través de las cosas plausibles concernientes a cada uno de ellos. Ahora bien, esto es

\footnotetext{
la ciencia antigua de la nat uraleza y la ciencia natural posterior a Galileo. es que los pensadores antiguos- prescindiendo totalmente de la diversidad de sus sistemasestuvieron atados siempre a principios de invariancia estáticos, mientras que después de Galileo todas las explicaciones de la regularidad en la naturaleza están fundadas sobre principios dinámicamente invariantes." I. Düring. O.C. pg. 320. No estoy muy seguro de que esto sea así exactamente y quizá pudiéramos hallar 1 Meteoros "el vaso de cera". "los barcos cargados en el mar que entran en los rios y viceversa". "agua extendida que se evapora más rápidamente"... etc) ejemplos de observaclones que ent rañan experimentación, $o$ algo equiparable, aducidas en apoyo de teorias. Mídea es que el Aristóteles de estos textos iniciales no se conserva más que en parte en otros muy posteriores.

${ }^{63}$ Si se reconoce una "Edición de Eudemo" para la Fisica en la que falta el lb. VII. es porque hubo otra edición distinta de la de Andrónico. cosa que no debió impedir el efecto arrasador que comentamos.
} 
propio o exclusivo de la dialéctica: en efecto, al ser adecuada para examinar <cualquier cosa>, abre camino a los principios de todos los métodos"64.

Es muy congruente con el resto de su obra la idea de que Aristóteles en los Segundos Analiticos contempla la forma en que hay que "sistematizar" los conocimientos. Pero estos no surgen por alguna milagrosa fórmula (Aristóteles rechaza las ideas y la anámnesis platónicas) distinta de lo que se entendia en los medios platónicos por "dialéctica". Y si esto es así, entonces algo tienen que ver "principios, causas y elementos" con los principios de la sistematización propuestos en los Analíticos. La dialéctica aristotélica (claramente deudora de y contrapuesta a la platónica) tiene un tinte "segundo-analitico" demasiado evidente como para ser desconocido. Pero la Fisica o la Metafisica no pueden ocultar su procedencia y hasta su destino dialécticos. Su estudio de la naturaleza (de la Physis en el sentido parmenideo mencionado más arriba, y también en el sentido aristotélico de principio de movimiento) en tanto que principio intimo o primero de ser (y de cambio) es un análisis de carácter dialéctico indiscutible. Y quizá sea mejor fijarse en el modo como elabora alguno de sus alegatos:

(6)

"Seria absurdo tratar de probar que existe la naturaleza, pues es evidente que existen muchas cosas de este tipo, y probar lo que es evidente por lo que no lo es la caracteristica del hombre incapaz de distinguir lo que es patente de lo que no lo es"65.

$\mathrm{Y}$ aún tendriamos algunos ejemplos más conspicuamente dialécticos cuando elabora definiciones:

(7)

"Hay pues tantas clases de movimientos y cambios como clases de ser.

${ }^{64}$ Trad. de Miguel Candel Sanmartin, en Tratados de Lógica I.pgs 92-93. Edit. Gredos. Madrid. 1982.

65 Fis. II. 1. 193a,3-6. En otras palabras. solo un tonto o un loco pedirá prueba de esto. $Y$ por extrana que pueda parecer una argumentación tan peculiar hay que recordar que no deja de estar recogida en los Tópicos. 
Distinguiendo respecto a cada uno de los géneros (de ser) la "entelejeia" y la potencia, la "entelejeia" en cuanto tal de lo que está en potencia, eso es el movimiento, como de lo alterado, en cuanto alterable, es la alteración... ${ }^{66}$.

En estos ejemplos hay que tomar nota de las flexiones de cada palabra: (traduciendo "entelejeia" por "actualización") hay que subrayar que cambio o movimiento es actualización; lo alterado ( $\alpha \alpha \lambda \lambda o 1 \omega \tau o v)$ ) en tanto que está siendo alterado es alteración ( $\alpha \lambda \lambda \sigma(\omega \sigma i \varsigma)$ y lo mismo para crecimiento y decrecimiento

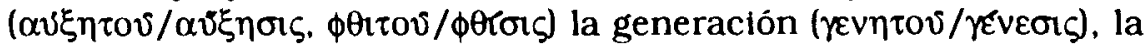

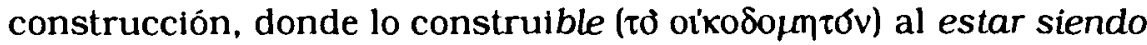

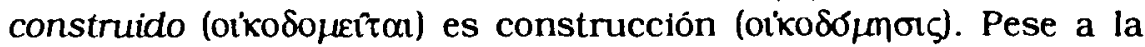
innegable sutileza en el manejo del lenguaje. la investigación aristotélica se centra en muchos de estos casos en hallar una manera de decir que no pueda ser objeto de controversia dialectica por parte de no sabemos qué replicantes ${ }^{67}$. Mientras que sí nos da a entender continuamente que, quienes fuesen ellos, habrian de hacerlo sobre presupuestos filosófico-dialécticos.

Curiosamente en algunos pocos lugares de la Fisica y del De Caelo ${ }^{68}$ se hallan presentaciones de argumentos con formato "analítico". Pero no mucho más tarde vuelve a su discurso dialéctico sin mayor continuidad en el anterior. No sé si es demasiado exagerado decir que la raiz de la ciencia aristotélica es genuinamente dialéctica, como la de sus interlocutores explicitos, aunque su herramienta "analitica" (usada aquí y allá, a veces muy brillantemente) le da alguna mayor contundencia a sus afirmaciones, a sus definiciones e incluso a sus atrevimientos. En todo caso, desde un

66 Fis. III. 1.201a, 8-12. El sentido de nuestra traducción es intencionado,pese al desacuerdo con las que hemos visto, para hacerla consistente con el final del párrafo en 20la.27-29.

67 Diría aqui que Aristóteles trata de construir un discurso "inmune a la réplica exterior e inmune a la contradicción interna". Pero esto implicaria un compromiso muy fuerte con la sociologia del conocimiento de esa segunda mitad del s.IV a.C. y personalmente no estoy en condiciones de asumirlo más que en el contexto de la Academia y sus corresponsales. Aunque quizá esto baste y sobre para mantener la tesis sociologista en su sentido pleno.

68 Por ejemplo en De Caclo 1.12.282a. 14 y stss. un típico argumento al modo

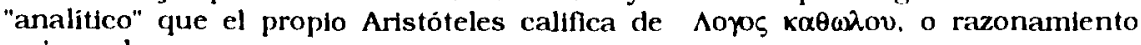
universal. 
punto de vista metodológico, el cientificismo aristotélico de los grandes textos "acroásticos" (dejo aparte a los textos biológicos) más parece "dialéctico" (en el sentido del término en aquel momento) que "segundo-analítico". La fórmula viene a ser siempre la misma: un término o definición en discusión se propone, se define, se compara con otras definiciones, se muestra que la nueva propuesta queda libre de objeciones o defectos de las anteriores, y queda incorporado, aunque sea provisionalmente, al elenco de términos disponibles $^{69}$.

Pero la insistencia aristotélica en la necesidad de definir $(\delta$ iop $\sigma \alpha \sigma \theta \alpha l)$ y la referencia a ese objetivo, incluso de la silogistica asumida en los Segundos Analiticos, me lleva a creer que las técnicas propuestas en Categorias, en Tópicos, o en Analiticos, no son enteramente autónomas, sino que representan meras estrategias, más poderosas desde luego, en la tarea de conocer y sistemati-

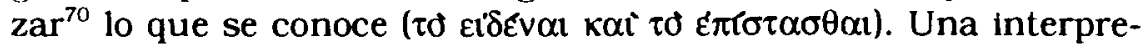

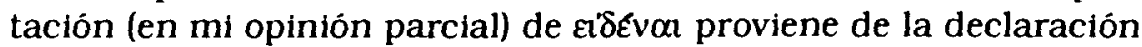

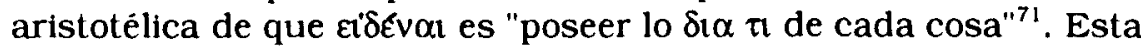
declaración ha sido interpretada no pocas veces como una especie de definición de $\varepsilon$ í́v́val, pero me parece más propio del caso dividir la declaración en dos:i) conocer es el término de un proceso

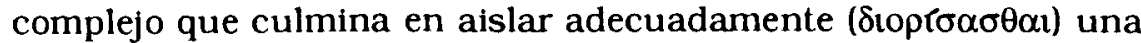
cosa: ii) uno de los caminos, quizá el más directo y completo tratándose de cosas naturales, es determinar sus factores, sus componentes factoriales. En tal caso las $\alpha i \tau i \alpha l$ antes que explicar,

69 Aunque con variaciones son muchos los ejemplos de este proceder tipicamente dialćctico. Puede verse un ejemplo en De Caelo III, 3.302a.14 y sts. en la definición de elemento (otoux₹10v).

70 Me parece que se puede hallar en la idea de "epistemizar" de Aristóteles un valor dialéctico consistente en que lo "epistemizado" resulta inmune a las ofensivas dialécticas de los posibles objetores. Por ello "epistemizar" parece entrañar. en Aristóteles. una consideración especial de las opiniones contrarlas y una inmuntzación de las propias frente a ellas.

71 Confer. Fis.II,3,194b, 19. En este texto la indecisión de la traducción de $\lambda \alpha \mu \beta \alpha v \omega$ ( $\lambda \alpha \beta o \mu \eta v$ en el texto),aleja de nosotros el matiz aristotélico: $\_$poseer, apoderarse, estimar...?. Si hay que "conseguir" el $\delta ı \alpha$ ti de cada cosa para conocer $(\varepsilon i \delta \varepsilon v \alpha \imath)$.parece que hay que suponer clerta distancia entre $\lambda \alpha \mu \beta \alpha v \omega$ y $\varepsilon ı \delta \varepsilon v \alpha l$ al igual

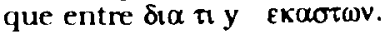


definen y, una vez definido, explican el sentido de la definición ${ }^{72}$. Por lo mismo la teoría de las cuatro causas no parece inicialmente solo una estrategia explicativa (demostrativa en términos aristotélicos), sino una estrategia dialéctica en busca de una definición ${ }^{73}$. Que la teoria de las causas se haya vinculado a la explicación y a la sistematización epistémica más que a la dialéctica heuristica de las definiciones a la que, según creo, perteneció originariamente, es una de las trampas en que ha caído la tradición de la episteme aristotélica, ( $\mathrm{y}$ en esto ha colaborado otro tanto la tradición platónico-judaica) ${ }^{74}$.

Es evidente que la lectura de la Peri Physeos Epistemes que vengo haciendo depende, sobre todo, de la Fisica Lb.I-II y algo del De Caelo Lib I-III. Y bien sé que, por ello, es forzosamente parcial, ya que los estudios naturales de Aristóteles son más amplios y darian lugar a matizar mucho la idea general propuesta aqui. Pero, con todo, no parece que en otros contextos pueda basarse un argumento decisivo en contra de la idea principal expuesta más arriba. En De Partibus Animalium ${ }^{75}$ (uno de los textos relacionados con Los Analiticos) afirma que "el modo de ser de la demostración y de la

72 Confer. Moravesik. Julius M.E. : "Aristotle on Adequate explanations" en Synthese 28. (1974). 3-17.

73 Ciertas dudas pueden caber sobre esta interpretación. sobre todo si se interpreta muy literalmente su declaración sobre el "pensar " del fisico y el "demostrar fisicamente" ( en términos de conocimiento físico): "Puesto que las

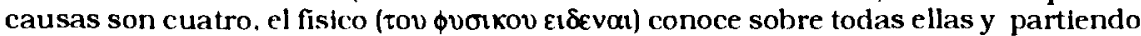
de ellas determina ( $\alpha \pi 0 \delta(1) \sigma \varepsilon t$ ) el por qué fisicamente (

74 I. Düring dice: "De manera tradicional se traduce aitía por causa y cada vez se añade la explicación de que no se trata de causas en el sentido actual del término. Solo el tercer principio (e.e. el eficiente) lo designariamos también nosotros como "causa". Aristóteles confunde frecuentemente causa cognoscendi y causa essendi. razón y causa. Siempre parte de que el saber presupone conocimiento del "porqué", dia tí 'Realizamos nuestra investigación para liegar al conocimiento:pero no pensamos conocer lo individual sino hasta que conocemos para cosa el porqué, y esto significa, captar la razón primera'. El concepto de privación. que juega un gran papel en Lambda y en el libro primero de la Fisica plerde importancia más tarde". I. Düring. Arstóteles. pg. 321 de la ed. en castellano. Llama aquí la atención la idea de que Aristóteles confundiese ser y conocer. Más bien habria que pensar en la carga teórica de que era portador al identificar ambos órdenes. Si suponemos esto ya no necesitariamos pedirle a Aristóteles que distingulese entre ambos, ni él mismo necesitaria distinguir para un oyente iniciado.

Partes de los Animales I,640a.1. 
necesidad es distinto para la fisica y para las ciencias teóricas". Pero no por ello se pierde la perspectiva, pues añade a continuación: "pues para lo uno el principio es lo que es y para lo otro el principio es lo que debe ser". Y ambos, ser y deber ser, alcanzan su definición en términos de "principios, causas o elementos". Y en un pasaje caracteristico Aristóteles se confiesa continuador de la tradición fisica en sus propios términos; dice asi:

(8)

"La causa de que nuestros predecesores no alcanzasen esta misma capacidad es que no podian definir ( $\omega$ p $[\sigma \alpha \sigma \theta \alpha)$ ni la

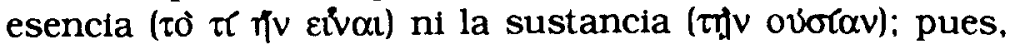
Demócrito lo intentó el primero,pero no como una necesidad de la teoria fisica,sino en tanto que arrastrado por la propia realidad práctica, y en tiempo de Sócrates se progresó en esto, pero la investigación sobre las cosas físicas desapareció, y los filósofos se volvieron hacia la virtud utilitaria y hacia la politica"76.

\section{REFERENCIAS BIBLIOGRÁFICAS.}

ALLAN D.J.:The Philosophy of Aristotle (29) Londres.Oxford 1970. U.Press.

APOSTLE H.:Aristotle's Philosophy of Mathematics. 1952. Chicagolll. Univ. of Chicago Press.

ANSCOMBE G.E.M y Geach P.T.:Three Philosophers.Basil Blackwell. 1961, Oxford. AgUINO, Th.: In Libros Physicorum Aristotelis expositio. Ed. Marietti. Turin-Roma. 1954.

AUBENQUE P.: El problema del ser en Aristóteles. 1962. Taurus. Madrid. 1974. (trad. de Vidal Peña).

BARNES J.M.(et alii) (Edts).:Articles on Aristotle. 1975. Duckworth. Londres.

BOURGEY L.: Observation et experience chez Aristote. Vrin. 1955. Paris.

BOYLAN M.: Method and Practice in Aristotel's Biology. 1983. Univ. of America Press.

Wasington.

BURNET, J.: L'Aurore de la Philosophie Greque. (Edic. francesa de Aug. Reymond) de Early Greek Philosophy. (1"1892-4" Londres (1948). Payot. Paris. 1970.

CHERNISS H.: Aristotle's Criticism of Presocratic Philosophy. 1935. Baltimore.

ID. id.: Aristotle's Criticism of Plato and the Academy. 1944 Baltimore.

CONIMBRICENSES: Commentarii. in octo libros physicorum Aristotelis. Lugduni. Sumptibus Joannis Baptistae Buysson. 1594. (reimp.) Georg Olms Verlag.Hildesheim. Zürich. N. York 1984.

${ }^{76}$ Partes de los Animales. I.,242a,24-31. 
DANCY R.M.: Sense and Contradiction:A Study in Aristotle. 1975. Reldel Pub.Comp. Dordrecht-Holanda.

DURING I. y Owen G.E.L.:"Aristotle and Plato in the Mid-fourth 1960. Century". Studia Gothoburgensia XI. Gotebörg.

DÜRING I: Aristoteles. Darstellung und Interpretation seines Denkens.Heidelberg. 1966. Trad. castellana: Aristóteles. Bernabé Navarro. U.N.A.M. México, 1987; 1990, 2.)

GLAGHORN G.S.: Aristotle's Criticism of Plato's Timaeus. 1964. Nijhoff.La Haya.

GRENE M.: A Portrait of Aristotle. 1ll.Univ.of Chicago. 1963 Press.Chicago.

HEATH T.: Mathematics in Aristotle. Oxford Univ. Press. 1949. Oxford.

JAEGER W.: Aristotle:Fundamentals of the History of his Development. 1934. Oxford Univ.Press.

KAPP E.: Greek Foundations of Traditional Logic..N.York. 1942.

LAUDAN L.:"Theories of Scientific Method from Plato to Mach" 1969. En History of Sctence. 7. pgs. 1-63.

LE BLOND J.M.:Logique et Methode chez Aristote. Paris . 1939.

LEAR J.: Aristotle and Logical Theory. Cambridge Univ. Press. 1980. Cambridge.

-id.1d.: Aristotle:the desire of understand.Cambridge Press. 1988. Cambridge.

LLOYD G.E.R.:Aristotle:The Growth and Structure of His Though 1968. Cambridge Univ.Press. Cambridge.

D.ID.: Aristotle on the Mind and the Senses. Cambridge. 1978. Univ. Press. Cambridge.

. id.: Polaridad y Analogia. Taurus .Madrid 1987. (1' ed. inglesa 1966).Trad. Luis Vega Reñón)

MANSION A.: Introduction à la Physique aristotelicienne. 24. 1946. Pub. Univ. Lovaina. MORAVCSIK,J.M.E.: "Arlstotle on Adequate Explanations" en Synthese, 28, 1974. OWENS J.: The Doctrine of Being in the Aristotelian Metaphysics. 1978. Pontifical Inst. of Mediaeval Stud.Toronto

PERELMAN C.:Traitè de l'argumentation. P.U.F. Paris. 1958.

RANDAL J.H.: Aristotle. Columbia Univ. Press. N.York. 1960.

ROSS W.D.: Aristotle's Physics. Clarendon Press. Oxfond. 1936.

-id.id.: Artstotle. Methuen. Londres.(5') 1949.

SOLMSEN F.:Aristotle's System of the Physical World. 1960. Cornell Univ. Press.Ithaca, N.York.

SYMPOSIUM.: Aristote et les problèmes de methode( (2') Edit. 1980. de l'Instit. Sup.de Philos. Louv. la Neuve.

WATERLOW,S.: Nature, Agency and Change in Artstotle's Physics. 1982.Clarendon Press Oxford. 